\title{
Managerial Preferences, Corporate Governance, and Financial Structure *
}

\author{
Hong Liu \\ Olin School of Business \\ Washington University in Saint Louis \\ Jianjun Miao \\ Department of Economics \\ Boston University
}

Last revised: March 16, 2006

Preliminary and incomplete

Journal of Economic Literature Classification Numbers: D11, D91, G11, C61.

Keywords: Managerial/entrepreneurial characteristics, ownership and capital structure, private benefits of control, corporate governance

\footnotetext{
${ }^{*}$ Comments welcome.
} 


\begin{abstract}
Conflicts of interest between insiders (e.g, controlling shareholders) and outsiders (e.g., minority shareholders) are central to the analysis of modern corporation. In an integrated continuous-time contingent claims framework with imperfect corporate governance, we examine a controlling shareholder's optimal choice of capital structure, ownership concentration, private benefit diversion, consumption, and financial market investment. We derive solutions in explicit parametric forms up to numerical integrations. In addition to generating implications consistent with existing empirical evidence, we also show that managerial preference characteristics (such as risk aversion and impatience), corporate governance, and financial market are important determinants of equity value, credit spread, agency costs, capital structure, and ownership concentration. Our model produces many novel empirically testable predictions. For example, it implies that a more risk averse or a less impatient entrepreneur issues less debt and more equity, and that stronger corporate governance leads to higher equity value, lower leverage, less ownership concentration, and lower credit spread. In addition, it also suggests that as the Sharpe ratio in the financial market increases, firm leverage ratio, agency costs, and credit spread all increase.
\end{abstract}




\section{Introduction}

Since Jensen and Meckling's (1976) seminal work, researchers have generally acknowledged that the conflicts of interests between insiders such as entrepreneurs/managers or controlling shareholders and outsiders such as minority shareholders are central to the analysis of modern corporation. The recent law and finance literature following Shleifer and Vishny (1997) and La Porta et al (1998) has studied the empirical implications of this agency problem for dividend policies, ownership structure, corporate valuation, investment allocation, and capital markets. This literature argues that the extent of legal protection afforded minority shareholders from expropriation by the controlling shareholders is important for corporate finance and has many cross-sectional implications in both firm level and country level data. There is also a growing empirical literature on how managerial characteristics can potentially affect corporate financing policies. For example, Graham and Harvey (2001) find empirical evidence that top management's characteristics such as age and tenure affect investment and capital structure decisions. McConaughy and Mishra (1999) document empirical evidence that funding family controlled firms (FFCFs) use less debt than non-FFCFs. Thomsen and Pedersen (2000) report empirical evidence supporting the hypothesis that the identity of large owners-family, bank, and institutional investors-has important implications for financial structure.

While the preceding literatures have documented extensive empirical evidence, not much research is devoted to developing quantifiable theoretical models of firms' investment and financing policies under agency conflicts where the interaction among managerial characteristics, corporate governance, and financial markets plays an important role. In this paper we develop such a model in a dynamic setting using the contingent claims framework. Our model is in the tradition of Black and Scholes (1973), Merton (1973, 1974), Black and Cox (1976), and Brennan and Schwartz (1978). It is also in the spirit of Mello and Parsons (1992), Leland (1994), and Goldstein, Ju and Leland (2001). Unlike these papers, in our model a risk averse, utility-maximizing entrepreneur (a controlling shareholder) can continuously divert corporate resources for his private benefits of control. We investigate how managerial preference characteristics, corporate governance, and financial markets affect important economic variables such as capital structure, ownership concentration, and credit spreads.

Specifically, we analyze a complete market model in which a risk averse entrepreneur decides 
whether to invest in a project to set up a firm. The entrepreneur finances the investment cost by issuing equity and debt. He is the controlling shareholder, while the outside shareholders are dispersed and hence referred to as minority shareholders. We assume that the entrepreneur derives utility from the usual consumption good and private benefits of control. ${ }^{1}$ Therefore there is a conflict of interest between the entrepreneur and the minority shareholders and the entrepreneur has an incentive to divert corporate resources as private benefits of control. Diversion creates inefficient investment and reduces equity value. However, legal protection of investors may reduce diversion activities. In addition, debt financing can mitigate the agency costs of equity because it raises the equity ownership of the entrepreneur and, in addition, reduces the free cash available to the entrepreneur for diversion. However, debt is also costly, because it mandates coupon payment and thus may force the entrepreneur to go bankrupt and lose the private benefits of control and future dividend income.

In addition to choosing his ownership of the firm, the entrepreneur can also invest his personal wealth in a riskfree asset and a frictionless stock market. The entrepreneur's problem is thus to determine ownership share and capital structure, and then to dynamically choose consumption, diversion, saving, stock investment strategies, and default time to maximize his expected lifetime utility. The tradeoff between the bankruptcy cost of debt and the tax advantage of debt plus the benefit from reducing the agency cost of equity results in a utilitymaximizing capital structure. In addition, the tradeoff between diversification and agency costs results in a utility-maximizing ownership structure.

We show that managerial preferences, corporate governance, and financial markets are important determinants of default policy, debt value, equity value, capital structure, ownership concentration, and credit spreads. First, our model implies that the entrepreneur's utilitymaximizing default policy depends on both firm cash flow level and the entrepreneur's personal wealth. This two-dimensional default boundary is in sharp contrast with the one-dimensional default boundary examined by most of the existing literature and provides a richer set of empir-

\footnotetext{
${ }^{1}$ We model the private benefits of control as distinct from the enjoyment of the usual consumption good, as in Jensen and Meckling (1976). The private benefits of control can take a variety of forms. For example, the entrepreneur may consume perquisites as in Jensen and Meckling (1976). He may expropriate outside minority shareholders by transfer pricing, asset stripping, and investor dilution. He may also install unqualified family members in managerial positions. We do not model private benefits of control as direct theft of profits put in his own pocket since this activity is illegal and can be detected relatively more easily. Proving these practices to be diversion for private benefits is usually costly, if not impossible.
} 
ically testable implications for financial structure and credit spreads as shown later. Intuitively, the benefit of default is the avoidance of the debt coupon payment and the cost of default is the loss of private benefits of control and dividend income. When the entrepreneur's wealth level is low, diversion and thus private benefits are also low because diversion reduces dividend income while the marginal utility of income is high. Therefore, when both the firm's cash flow and the entrepreneur's wealth level are sufficiently low, the present values of private benefits and dividend income are low, and hence the entrepreneur optimally defaults to avoid the coupon payment.

Second, our model implies that debt value, equity value, capital structure, ownership concentration, and credit spreads are sensitive to managerial preference characteristics. For example, a more risk averse or a more patient entrepreneur issues less debt and more equity and thus it implies a lower credit spread for the debt. Intuitively, a more risk averse entrepreneur owns less of the firm and issues less debt for the aversion to cash flow risk and bankruptcy risk. A more patient entrepreneur consumes less and diverts less and thus equity value is higher, which makes it more attractive to issue equity. This result provides new determinants of capital structure and may help explain the cross sectional differences of capital structure observed in practice (e.g., Rajan and Zingales (1995) and Graham and Harvey (2001) ). ${ }^{2}$

Third, we show that stronger corporate governance is associated with higher equity value, less concentration of ownership, lower leverage, and lower credit spreads. The first three relationships are consistent with the empirical evidence documented by La Porta et al $(1999,2002)$ and Berger et al (1997). The last relationship seems a novel testable prediction. In contrast to the standard structural models on capital structure (e.g., Collin-Dufresne and Goldstein (2001) and Huang and Huang (2003)), our model can generate high credit spreads as observed in practice, due to the additional agency costs.

Fourth, in our model stock markets influence the firm's financing and investment decisions and also credit spreads, by affecting the entrepreneur's wealth, perceived risk, and hence his decision making. We show that a stock market with higher market price of risk is associated with higher leverage and higher credit spreads. This implication may be tested using the crosscountry data. Intuitively, with a higher Sharpe ratio, the entrepreneur invests more in the

\footnotetext{
${ }^{2}$ The impatience parameter in our model can be interpreted as mortality rate and thus can be viewed as a proxy for age.
} 
stock market and expects a higher risk-adjusted return and thus a greater future consumption. He therefore increases his current consumption and private benefit diversion to smooth intertemporal consumption. This increase in diversion decreases equity value and necessitates more debt financing which implies greater credit spreads.

Our paper is related to several strands of literature. First, it contributes to the literature of the contingent claims approach to capital structure. ${ }^{3}$ In this approach, an analysis is typically conducted in a risk-neutral world with a complete market and hence managerial preferences such as risk aversion and impatience does not matter. Most papers in this literature focus on the agency conflicts between shareholders and debtholders, such as the asset substitution problem (Jensen and Meckling (1976)) and the underinvestment problem (Myers (1977)). Recent work by Leland (1998) and Parrino and Weisbach (1999) has shown that the agency costs arising from these agency conflicts are too small to explain firms' financing decisions. Morellec (2004) studies the agency conflicts between managers and shareholders. He analyzes the implications of the free cash flow problem and managerial entrenchment for financing policies. Unlike our paper, he assumes that the level of private benefits of control is exogenously given and managerial risk aversion does not matter. While our paper also assumes complete markets, in our model managerial characteristics matter for investment and financing decisions because these characteristics determine their diversion behavior and hence the utility-maximizing default policy. ${ }^{4}$ Parrino, Poteshman and Weisbach (2005) also analyze the agency conflicts between managers and shareholders and emphasizes the importance of managerial risk aversion and wealth. Unlike our paper, they assume that the entrepreneur maximizes utility from wealth at the exercise time of the executive stock option. They do not model the manager's consumption, diversion, and portfolio choice decisions.

Second, our paper is related to the law and finance literature mentioned earlier. This

\footnotetext{
${ }^{3}$ This literature has developed substantially. Mello and Parsons (1992) and Leland (1994) endogenize shareholders' default decision and determine optimal capital structure. Leland and Toft (1996) analyze finite maturity debt. Fischer, Heinkel and Zechner (1989), Leland (1998), Goldstein, Ju and Leland (2001), and Ju et al (2005) consider optimal dynamic capital structure. Duffie and Lando (2001) incorporate imperfect information and learning. Fan and Sundaresan (2000), François and Morellec (2004), and Hege and Mella-Barral (2003) analyze the effects of strategic default. Hackbarth, Miao and Morellec (2005) analyze the impact of macroeconomic conditions on capital structure. Fries, Miller and Perraudin (1997), Lambrecht (2001), and Miao (2005) investigate the interaction between capital structure and product market competition.

${ }^{4}$ Risk aversion also matters for investment and financing decisions with asymmetric information and incentive problems (Leland and Pyle (1977) and Ross (1977)), or under incomplete markets (Henderson (2005), Hugonnier and Morellec (2005), and Miao and Wang (2005)).
} 
literature has so far focused mostly on empirical questions. We contribute to this literature by providing a quantifiable theoretical model of financing and investment polices in a dynamic setting. In addition to obtaining results consistent with existing empirical evidence, we provide some novel results that have testable empirical implications.

Finally, our paper is also related to the portfolio choice literature. Different from a standard portfolio choice model (e.g., Merton (1971)), our model requires to solve a two-dimensional combined optimal control and stopping problem, which is technically challenging in general. The usual dynamic programming method does not permit a closed-form solution and requires complicated numerical methods such as the PDE method. Instead, we generalize the dual approach in Dybvig and Liu (2006) to derive the explicit two-dimensional default boundary and provide closed-form valuation formulas that can be easily implemented in numerical computation.

The remainder of the paper proceeds as follows. Section II sets up the model and analyzes a benchmark case with perfect corporate governance. Section III presents the model solution. Section IV analyzes the model's implications. Section V concludes. Proofs are relegated to appendices.

\section{The Model}

In this section, we first describe the model setup and then present the solution for a benchmark model with perfect corporate governance.

\section{A Setup}

Consider an entrepreneur's investment and financing decisions in a continuous-time infinitehorizon model. The entrepreneur has a take-it-or-leave-it investment project and decides whether to invest in this project at time 0 . If he makes the investment, he sets up a corporate firm. We assume that he does not have sufficient wealth to finance this investment. Thus, he needs outside sources of financing. We formulate this investment and financing decision problem step by step in what follows.

\section{A.1 Equity and Debt Financing}

Let the investment cost be $I>0$. The entrepreneur has initial wealth $w_{0}<I$. He contributes wealth $\bar{w}$ and retains wealth $w$ for consumption purpose. He finances the net cost $I-\bar{w}$ by 
issuing debt and equity. Suppose he retains $\alpha \in(0,1)$ shares of equity and issues $1-\alpha$ shares of outside equity. In addition, he may issue a perpetual debt at par value $D_{0}$ with a coupon rate of $c$ (as in Leland (1994) and Duffie and Lando (2001)). The cash flows from operation net of the coupon payment accrue to the equity holders. The entrepreneur's firm is subject to corporate taxes at the rate $\tau_{c}{ }^{5}$ Because interest payments are tax deductible, debt has tax advantage. Even without tax advantage, debt may also be used to finance investment if equity is not sufficient to cover the investment cost. Of course, debt is costly since it may cause bankruptcy and make the entrepreneur lose the private benefit of control and the dividend stream. We assume that if the firm defaults on its debt obligation, it is immediately liquidated. The liquidation value of the firm's assets is equal to a constant fraction $\nu$ of the unlevered (aftertax) market value of the firm. The remaining fraction $(1-\nu)$ accounts for bankruptcy costs. Assume that absolute priority is enforced. By limited liability, upon default the debtholders obtain the liquidation value and the entrepreneur loses control of the firm and receives nothing. In addition, for simplicity we also assume that after default, the entrepreneur does not receive any labor income and does not have any other projects for investment.

Once the firm is set up, it can generate stochastic cash flows $Y_{t}$ at time $t$. Assume that $\left\{Y_{t}: t \geq 0\right\}$ is governed by the following geometric Brownian motion process:

$$
d Y_{t}=\mu_{y} Y_{t} d t+\sigma_{y} Y_{t} d B_{t}, Y_{0}=y_{0}
$$

where $\mu_{y}$ and $\sigma_{y}$ are constants and $B_{t}$ is a standard Brownian motion.

\section{A.2 Financial Markets}

Since the entrepreneur faces cash flow risk, he may trade risky assets in the financial market to diversify this risk. For tractability, we consider a complete market environment. Specifically, we assume that the entrepreneur may trade a risk-free bond with a constant risk-free rate $r>0$. In addition, he may trade a market portfolio with returns satisfying

$$
d S_{t} / S_{t}=\mu d t+\sigma d B_{t}
$$

\footnotetext{
${ }^{5}$ We abstract from personal taxes in the present paper since a thorough analysis of corporate and personal taxes is beyond the scope of the present paper.
} 
where $\mu>r$ and $\sigma>0$ are constants. Note that the cash flow risk is perfectly correlated with the market risk and both are represented by the single Brownian motion $B{ }^{6}$

Define the Sharpe ratio $\kappa=\sigma^{-1}(\mu-r)$. Since the markets are complete, there is a unique state price density process $\xi$ satisfying

$$
-d \xi_{t} / \xi_{t}=r d t+\kappa d B_{t}, \quad \xi_{0}=1
$$

We impose the following assumption so that the unlevered firm value is finite.

\section{Assumption 1 Let}

$$
\delta \equiv r+\sigma_{y} \kappa-\mu_{y}>0
$$

The parameter $\delta$ may be interpreted as the dividend yield or payout rate of the firm. This is because by the CAPM, the market risk-adjusted expected rate of return on $Y$ is given by $r+\sigma_{y} \kappa$. Since $\mu_{y}$ represents the capital gain of $Y, \delta$ is the dividend rate. As is standard in the literature, we fix $\delta$ as a fundamental parameter of the process $Y$ when we do comparative statics analysis with $\sigma_{y}$ or $\kappa$. We may also rewrite (1) as

$$
d Y_{t}=(r-\delta) Y_{t} d t+\sigma_{y} Y_{t} d B_{t}^{Q}, Y_{0}=y_{0},
$$

where $B^{Q}$ is the Brownian motion under the risk-neutral measure $Q$. Then it is straightforward to show that under Assumption 1 the unlevered firm value is given by

$$
L_{t}=\xi_{t}^{-1} \mathbb{E}_{t}\left[\int_{t}^{\infty} \xi_{s} Y_{s} d s\right]=\frac{Y_{t}}{\delta}
$$

where $\mathbb{E}_{t}$ denotes the expectation operator condition on the information available at date $t$.

\section{A.3 Preferences}

Since the entrepreneur is the founder of the firm, he represents a controlling shareholder and hence has the decision power over the firm's financing and investment policies. As in Shleifer and Wolfenzon (2002), we assume that the entrepreneur retains the control of the firm regardless of the fraction of the cash flow rights he may sell to the outside investors. When the entrepreneur manages the firm, he may appropriate perquisites out of the firm's resources for his private

\footnotetext{
${ }^{6}$ It is straightforward to generalize our model to allow multiple risky assets as long as market completeness is maintained. However, introduction of multiple risky assets does not change our main qualitative results.
} 
benefits of control. As pointed out by Jensen and Meckling (1976, p.312), these benefits "involve not only the benefits he derives from pecuniary returns but also the utility generated by various non-pecuniary aspects of his entrepreneurial activities such as the physical appointments of the office, the attractiveness of the secretarial staff, the level of employee discipline, the kind and amount of charitable contributions, personal relations ("love", "respect", etc.) with employees, a larger than optimal computer to play with, purchase of production inputs from friends, etc." To incorporate these private benefits of control, we assume that the entrepreneur derives utility from both the usual consumption good and the private benefits of control. In particular, he has instantaneous utility given by

$$
U(C, X)=\frac{\left(a X^{\varphi}+C^{\varphi}\right)^{\frac{1-\gamma}{\varphi}}}{1-\gamma}, X \geq 0, C>0 .
$$

where $\gamma>0, \gamma \neq 1, a>0$, and $\varphi \in(0,1)$. The interpretation of this utility is the following. The entrepreneur is risk averse and has the risk aversion parameter $\gamma$. He derives utility from consumption $C>0$ and perquisites $X \geq 0$. The elasticity of substitution between consumption and perquisites is given by $1 /(1-\varphi)$. The parameter $a$ represents the preference for private benefits.

When the firm is liquidated, the entrepreneur loses all private benefits $(X=0)$ and thus his utility is given by

$$
U(C, 0)=\frac{C^{1-\gamma}}{1-\gamma}
$$

\section{A.4 Diversion and Agency Issues}

Diversion is costly for the entrepreneur. For example, it may require transaction costs and take legal risks. We assume that when the entrepreneur diverts $X$ units of corporate resources as perquisites, he only obtains $(1-q) X$ units of benefits, where $q \in[0,1]$. Thus, he derives instantaneous utility $U(C,(1-q) X)$. The amount $q X$ accounts for the cost of diversion and

$q$ represents the quality of corporate governance. A higher value of $q$ means that the quality of corporate governance is better, and hence it is more costly to divert. When $q=1$, diversion is so costly that the entrepreneur cannot derive any private benefit, and thus he will not divert. Thus, $q=1$ represents the case of perfect corporate governance.

When the entrepreneur sells a fraction of the firm's cash flow rights to the outsiders, agency cost is generated by the divergence between his interest and those of the outside shareholders, 
since he bears only a fraction of the costs of any private benefits he takes out to increase his own utility. To see this formally, suppose the entrepreneur owns $\alpha$ shares of the firm and sells $1-\alpha$ shares to the outsiders. At date $t$, if he diverts $X_{t}$ of cash flows, he obtains dividends $\alpha\left(Y_{t}-X_{t}-c\right)$ at date $t$. Thus, he bears the cost $\alpha X_{t}$ instead of $X_{t}$. Because the outside minority shareholders receive dividends $(1-\alpha)\left(Y_{t}-X_{t}-c\right)$, they bear a cost of $(1-\alpha) X_{t}$.

\section{A.5 Decision Problem}

We now describe formally the entrepreneur's decision problem. We first introduce some notation. Let $\left\{W_{t}: t \geq 0\right\}$ denote the entrepreneur's financial wealth process, $\left\{C_{t}: t \geq 0\right\}$ denote his consumption process, $\left\{X_{t}: t \geq 0\right\}$ denote his diversion process, and $\theta_{t}$ denote the dollar amount invested in the market portfolio at time $t$. We then describe the entrepreneur's problem after he has made the financing and the project investment decisions. Since the firm has to service debt repayment $c$ each period, when the cash flow is low enough, equity claims to the shareholders $\left(Y_{t}-X_{t}-c\right)$ may be negative. This means that shareholders must inject additional funds in the firm. Because the entrepreneur is the controlling shareholder and hence makes the default decision, at some point in time, he may stop injecting funds and choose to default. We denote the default time by $T_{d}$.

Before this default time $T_{d}$, the entrepreneur receives dividends from the firm, and also receives returns from the bond and the market portfolio. Thus, his wealth dynamics is given by

$$
d W_{t}=\left(r W_{t}+\theta_{t}(\mu-r)+\alpha\left(1-\tau_{c}\right)\left(Y_{t}-X_{t}-c\right)-C_{t}\right) d t+\theta_{t} \sigma d B_{t}, \quad t<T_{d}
$$

This equation implies that the entrepreneur holds the fraction $\alpha$ of the firm equity, and thus receives after-tax claims $\alpha\left(1-\tau_{c}\right)\left(Y_{t}-X_{t}-c\right)$. Since we assume markets are complete and the entrepreneur can trade spanning assets, it does not matter whether or not the entrepreneur can trade the firm's shares. After default, the entrepreneur loses control of the firm and receives no income. But he may still trade the bond and the market portfolio. Thus, his wealth dynamics satisfies

$$
d W_{t}=\left(r W_{t}+\theta_{t}(\mu-r)-C_{t}\right) d t+\theta_{t} \sigma d B_{t}, t \geq T_{d}
$$

After debt is in place and the firm is set up, the entrepreneur chooses how much to consume, how much to divert, how much to save, and how much to allocate in the market portfolio. He 
also chooses when to default on the debt. That is, the entrepreneur chooses $\left\{C_{t}: t \geq 0\right\}$, $\left\{X_{t}: t \geq 0\right\},\left\{\theta_{t}: t \geq 0\right\}$, and $T_{d}$ to maximize his expected lifetime utility

$$
\mathbb{E}\left[\int_{0}^{T_{d}} e^{-\rho t} U\left(C_{t},(1-q) X_{t}\right) d t+\int_{T_{d}}^{\infty} e^{-\rho t} U\left(C_{t}, 0\right) d t\right],
$$

subject to the dynamic budget constraints (9)-(10) and the initial wealth condition $W_{0}=w$. Here, $\rho>0$ is the discount rate. It can also be interpreted as the sum of the subjective discount rate and the entrepreneur's mortality rate.

To rule out arbitrage strategies such as the doubling strategy (Dybvig and Huang (1986)), we impose a borrowing constraint

$$
W_{t} \geq-L_{t}
$$

This constraint means that the entrepreneur is allowed a limited amount of borrowing up to the unlevered firm value. It turns out that this constraint is never binding at optimum. Note that we do not impose other form of binding borrowing constraints in order to keep the analysis tractable.

We now turn to the entrepreneur's initial investment and financing decisions. Initially, the entrepreneur chooses how much debt to issue and how many shares to sell to outsiders. We first consider how debt and equity are priced in the market. Because the financial markets are complete, the market value of debt at date $t$ is given by

$$
D_{t}=\xi_{t}^{-1} \mathbb{E}_{t}\left[\int_{t}^{T_{d}} \xi_{s} c d s+\xi_{T_{d}} \nu\left(1-\tau_{c}\right) L_{T_{d}}\right]
$$

This equation says that debt value is equal to the present discounted value of coupon payments before default, plus the liquidation value upon default. Note that we assume that debtholders have rational expectations and take the optimal default policy of the entrepreneur as given. Thus, par value of debt must be equal to the initial market value of debt. We also assume that outside shareholders have rational expectations. The outside shareholders will buy the share at the market value given by

$$
E_{t}=\left(1-\tau_{c}\right) \xi_{t}^{-1} \mathbb{E}_{t}\left[\int_{t}^{T_{d}} \xi_{s}\left(Y_{t}-X_{t}-c\right) d s\right] .
$$

Given debt value and equity value in (13)-(14), we can write the financing constraint as

$$
(1-\alpha) E_{0}+D_{0}=I-\bar{w}
$$


The entrepreneur's initial decision is then to choose ownership shares $\alpha$ and coupon rate $c$ to maximize his life-time utility, subject to the preceding financing constraint.

\section{B The Benchmark with Perfect Corporate Governance}

As a benchmark, we first consider the case where corporate governance is perfect. In our model, this case happens when $q=1$, and hence there is no diversion $(X=0)$. To ensure that the value function is finite, we assume that the life-time utility from consuming cash flows $Y_{t}$ is finite since this utility gives an upper bound for the value function. A sufficient condition for this is given by

Assumption 2 Suppose

$$
\rho+\frac{1}{2} \gamma(1-\gamma) \sigma_{y}^{2}-(1-\gamma) \mu_{y}>0
$$

Since $X=0$, we can rewrite the utility function (11) as

$$
\mathbb{E}\left[\int_{0}^{\infty} e^{-\rho t} U\left(C_{t}, 0\right) d t\right]
$$

We can also rewrite the dynamic budget constraints (9)-(10) as a static Arrow-Debreu budget constraint (Cox and Huang (1989)):

$$
\mathbb{E}\left[\int_{0}^{\infty} \xi_{t} C_{t} d t\right] \leq w+\alpha \mathbb{E}\left[\int_{0}^{T_{d}} \xi_{t}\left(1-\tau_{c}\right)\left(Y_{t}-c\right) d t\right]
$$

Note that the second term on the right side of (18) is the market value of equity owned by the entrepreneur. Equation (18) also implies that the entrepreneur's consumption and portfolio choice is separable from the default and the initial (real) investment and financing decisions in the following sense. The entrepreneur first makes investment and financing decisions and forms optimal default policy to maximize his equity value. He then chooses consumption and given the resulting maximized equity value as wealth.

Here, we focus on the former set of decisions. We solve these decisions backward. After choosing an ownership share $\alpha$ and a coupon rate $c$, the entrepreneur selects a default policy $T_{d}$ to maximize his equity value:

$$
\max _{T_{d}} \alpha\left(1-\tau_{c}\right) \mathbb{E}\left[\int_{0}^{T_{d}} \xi_{t}\left(Y_{t}-c\right) d s\right]
$$


He then chooses $(\alpha, c)$ to maximize this equity value subject to the financing constraint (15). These problems are similar to Leland (1994) and Goldstein et al (2001). Importantly, when there is an interior solution for $\alpha$, it is straightforward to show that the choice of $c$ is equivalent to maximizing firm value $F_{0} \equiv E_{0}+D_{0}$. Note that with perfect corporate governance, there is no conflict of interest between the entrepreneur and outside equityholders. However, there is still conflict of interest between the entrepreneur and the debtholders because the entrepreneur chooses a default policy to maximize equity value instead of firm value.

The following proposition presents the equity-miximizing default policy and the valuemaximizing financing policy.

Proposition 1 Suppose $q=1$. For any coupon rate $c$, the entrepreneur defaults at the first time when the process $Y$ reaches the trigger $y_{d}(c)$ from above, where

$$
y_{d}(c)=\frac{\pi_{1}}{\pi_{1}-1} \frac{\delta c}{r}
$$

Here, $\pi_{1}$ is given by

$$
\pi_{1}=0.5-\sigma_{y}^{-2}(r-\delta)-\sqrt{\sigma_{y}^{-4}\left(r-\delta-\sigma_{y}^{2} / 2\right)^{2}+2 r \sigma_{y}^{-2}}<0 .
$$

The firm-value-maximizing coupon rate $c^{*}$ is given by

$$
c^{*}=y_{0} \frac{r}{\delta} \frac{\pi_{1}-1}{\pi_{1}}\left[1-\pi_{1}-(1-\nu)\left(1-\tau_{c}\right) \pi_{1} / \tau_{c}\right]^{1 / \pi_{1}} .
$$

Let $y_{d}^{*}=y_{d}\left(c^{*}\right)$. Given coupon rate $c^{*}$, equity value, debt value and firm value are given by ${ }^{7}$

$$
\begin{gathered}
E(y)=\left(1-\tau_{c}\right)\left[\left(\frac{y}{\delta}-\frac{c^{*}}{r}\right)+\left(\frac{c^{*}}{r}-\frac{y_{d}^{*}}{\delta}\right)\left(\frac{y}{y_{d}^{*}}\right)^{\pi_{1}}\right], y \geq y_{d}^{*}, \\
D(y)=\frac{c^{*}}{r}-\left[\frac{c^{*}}{r}-\left(1-\tau_{c}\right) \nu \frac{y_{d}^{*}}{\delta}\right]\left(\frac{y}{y_{d}^{*}}\right)^{\pi_{1}}, y \geq y_{d}^{*}, \\
F(y)=\left(1-\tau_{c}\right) \frac{y}{\delta}+\frac{\tau_{c} c^{*}}{r}\left[1-\left(\frac{y}{y_{d}^{*}}\right)^{\pi_{1}}\right]-\left(1-\tau_{c}\right)(1-\nu) \frac{y_{d}^{*}}{\delta}\left(\frac{y}{y_{d}^{*}}\right)^{\pi_{1}}, y \geq y_{d}^{*} .
\end{gathered}
$$

Equations (20) and (22) imply that a higher corporate tax rate gives more tax benefits to debt and hence encourages a higher debt level $\left(d c^{*} / d \tau_{c}>0\right)$. This in turn implies a higher

\footnotetext{
${ }^{7}$ Without risk of confusion, we use $E(y), D(y)$ and $F(y)$ to denote equity value, debt value and firm value, respectively, when the current value of cash flows is $y$.
} 
default threshold $y_{d}^{*}$. A larger bankruptcy cost (indicated by a smaller $\left.\nu\right)$ discourages debt $\left(c^{*}\right.$ is lower) and hence implies a lower default threshold $y_{d}^{*}$.

Equation (23) shows that equity value is equal to the after-tax value of unlevered firm value minus the present value of the perpetual coupon payments plus an option value to default. The term $\left(y / y_{d}^{*}\right)^{\pi_{1}}$ may be interpreted as the "risk-neutral" probability of default or the ArrowDebreu price of a unit of claim contingent on the event of default. Equation (24) shows that debt value is equal to the present discounted value of perpetual coupon payments minus the value reduction due to default, adjusted with the "risk-neutral" probability of default $\left(y / y_{d}^{*}\right)^{\pi_{1}}$. Equation (25) demonstrates that levered firm value is equal to after-tax unlevered firm value plus the probability-adjusted tax shields minus probability-adjusted bankruptcy costs.

We now turn to the entrepreneur's initial investment decision and the choice of $\alpha$. There are three cases. If the net investment cost satisfies $F\left(y_{0}\right)<I-\bar{w}$, then the entrepreneur will not make the investment to set up the firm since the financing constraint (15) is violated. If the net investment cost satisfies $D\left(y_{0}\right) \geq I-\bar{w}$, then the entrepreneur will hold all shares $\alpha^{*}=1$ and issue debt (or choose the minimum coupon rate $c$ ) such that $D_{0}=I-\bar{w}$. He will make the investment if equity value is higher than his own initial contribution, $E_{0}>\bar{w}$.

The most interesting case is where $F\left(y_{0}\right)>I-\bar{w}>D\left(y_{0}\right) \cdot{ }^{8}$ In this case, we can solve for an interior ownership share using the financing constraint to obtain

$$
\alpha^{*}=\left(F\left(y_{0}\right)-I+\bar{w}\right) / E\left(y_{0}\right) \in(0,1) .
$$

The entrepreneur will set up the firm if the life-time utility derived from owning the firm exceeds the life-time utility without setting up the firm. This condition is equivalent to

$$
\alpha^{*} E\left(y_{0}\right)+w>\bar{w}+w
$$

which is the standard net present value (NPV) rule $F\left(y_{0}\right)>I$ using (26).

If there is no corporate $\operatorname{tax} \tau_{c}=0$, then there is no tax advantage to debt. Since debt has bankruptcy cost, the entrepreneur will not issue any debt. It is straightforward to show that the solution has two cases. If the value of unlevered firm satisfies $L_{0}>I$, then the entrepreneur makes the investment and chooses $\alpha^{*}=1-(I-\bar{w}) / L_{0}$. If $L_{0}<I$, the entrepreneur does not make the investment.

\footnotetext{
${ }^{8}$ We will focus on this case in Section IV below.
} 
It is worth emphasizing that in contrast to the benchmark case, in the case with agency costs analyzed below, there may still be a role for debt, even if there is no corporate tax. In order to finance the investment cost, the entrepreneur trades off the cost of losing private benefits of control against the bankruptcy cost of debt.

\section{Model Solution}

In this section, we analyze the model with imperfect corporate governance. We solve the entrepreneur's problem by backward induction. We first solve the problem after default in Subsection A. This problem is a standard consumption and portfolio choice problem similar to Merton (1971). We then solve the problem before default but after the entrepreneur has made the investment and financing decisions at date zero in Subsection B. We will determine the optimal default time and diversion rate, in addition to the usual consumption and portfolio choice. We finally solve the date zero investment and financing decisions in Subsection C.

\section{A Decision Problem After Default}

After default, the firm is liquidated. The entrepreneur does not obtain any other labor income. His decision problem can then be described by the standard Merton-style consumption/portfolio choice model. We present this standard model as follows:

$$
\max _{C, \theta} \mathbb{E}\left[\int_{0}^{\infty} e^{-\rho t} U\left(C_{t}, 0\right) d t\right]
$$

subject to the budget constraint:

$$
d W_{t}=\left(r W_{t}+\theta_{t}(\mu-r)-C_{t}\right) d t+\theta_{t} \sigma d B_{t}, W_{0}=W .
$$

In addition, we specify the borrowing constraint $W_{t} \geq 0$ to rule out arbitrage strategies as in Dybvig and Liu (2006). Let $V^{d}(W)$ denote the primal value function after default, starting with the wealth level $W$.

The preceding problem can be solved by several methods and the solution is well known. Since it is convenient to solve the problem before default using the duality method in the next subsection, we also adopt this method here. We provide some heuristic argument to make it self-contained. 
The first step of the duality method is to transform the preceding dynamic problem into a static Arrow-Debreu problem (Cox and Huang (1989)) by rewriting the dynamic budget constraint (29) as a static Arrow-Debreu budget constraint:

$$
\mathbb{E}\left[\int_{0}^{\infty} \xi_{t} C_{t} d t\right] \leq W
$$

The second step is to use the Saddle Point Theorem to write

$$
V^{d}(W)=\min _{\lambda>0} \max _{C} \mathbb{E}\left[\int_{0}^{\infty}\left(e^{-\rho t} U\left(C_{t}, 0\right)-\lambda \xi_{t} C_{t}\right) d t\right]+\lambda W,
$$

where $\lambda \geq 0$ is the Lagrange multiplier associated with (30). To solve this problem, we let $z_{0}=\lambda$ and define the process $\left\{z_{t}: t \geq 0\right\}$ as

$$
z_{t}=z_{0} \xi_{t} e^{\rho t}
$$

This process can be interpreted as the entrepreneur's shadow price process for the consumption plan or equivalently the implicit Arrow-Debreu prices for time-and-state contingent consumption plans. We use this process as the state variable, instead of the usual wealth process. By (3) and (32), this process satisfies

$$
d z_{t} / z_{t}=-(r-\rho) d t-\kappa d B_{t}
$$

We also define the convex conjugate function as

$$
\tilde{u}(z) \equiv \max _{C} U(C, 0)-z C .
$$

The first-order condition implies that $z$ is equal to the marginal utility of consumption. Given the utility function defined in (8), we can easily show that

$$
\tilde{u}(z)=-\frac{z^{b}}{b}
$$

where $b \equiv 1-1 / \gamma$. It is easy to check that $\tilde{u}$ is strictly decreasing and strictly convex.

After defining the following dual value function

$$
\phi^{d}(z)=\mathbb{E}\left[\int_{t}^{\infty} e^{-\rho(s-t)} \tilde{u}\left(z_{s}\right) d s \mid z_{t}=z\right],
$$

we can rewrite problem (31) as

$$
V^{d}(W)=\min _{z_{0} \geq 0} \phi^{d}\left(z_{0}\right)+z_{0} W
$$


Thus, in order to the solve the primal problem (28), we only need to solve the dual problem (37). The key is to solve for $\phi^{d}(z)$ in $(36)$.

As in Merton (1971), for the investor's problem to have finite value, we need to impose the following assumption:

\section{Assumption 3 Let}

$$
\eta \equiv \frac{\gamma}{\rho-(1-\gamma)\left(r+\frac{\kappa^{2}}{2 \gamma}\right)}>0
$$

The following proposition gives the closed-form solution.

Proposition 2 After default, the primal and dual value functions are given by

$$
\begin{aligned}
V^{d}(W) & =\eta^{\gamma} \frac{W^{1-\gamma}}{1-\gamma} \\
\phi^{d}(z) & =-\eta \frac{z^{b}}{b} .
\end{aligned}
$$

The utility-maximizing consumption and portfolio processes are given by

$$
\frac{C_{t}}{W_{t}}=\frac{1}{\eta}, \text { and } \frac{\theta_{t}}{W_{t}}=\frac{\mu-r}{\gamma \sigma^{2}}
$$

The utility-maximizing wealth process is given by

$$
W_{t}=-\phi_{z}^{d}\left(z_{t}\right)
$$

where the shadow price process is given by

$$
z_{t}=\left(\frac{\eta}{W}\right)^{\gamma} \xi_{t} e^{\rho t}
$$

\section{B Utility-Maximizing Consumption/Portfolio and Default Policies}

We now turn to the decision problem before default, but after the initial investment and financing decisions have been made. Within this subsection, we hold the ownership share $\alpha$ and the coupon rate $c$ fixed. Since the entrepreneur makes both consumption/portfolio and default choices, the entrepreneur's problem is a two-dimensional combined stopping and control problem. In general, this is a technically challenging problem. In principle, one can apply the 
dynamic programming method to solve this problem. However, one usually has to resort to numerical methods and very few characterization results can be derived.

Instead, we adopt the duality method to solve this problem and provide an explicit solution to the default boundary. We also derive many characterization results. To apply this method, we first use the dynamic programming principle to rewrite the problem as

$$
V(w, y) \equiv \max _{\left(C_{t}, X_{t}, \theta_{t}, T_{d}\right)} \mathbb{E}\left[\int_{0}^{T_{d}} e^{-\rho t} U\left(C_{t},(1-q) X_{t}\right) d t+e^{-\rho T_{d}} V^{d}\left(W_{T_{d}}\right)\right],
$$

subject to $W_{0}=w, Y_{0}=y$, the dynamic budget constraint (9), and the borrowing constraint (12). Here $V(w, y)$ denotes the primal value function before default. We then transform this dynamic problem into a static Arrow-Debreu problem by rewriting the dynamic budget constraint (9) as a static one

$$
\mathbb{E}\left[\int_{0}^{T_{d}} \xi_{t} C_{t} d t+\xi_{T_{d}} W_{T_{d}}\right] \leq w+\alpha \mathbb{E}\left[\int_{0}^{T_{d}} \xi_{t}\left(1-\tau_{c}\right)\left(Y_{t}-X_{t}-c\right) d t\right]
$$

The first-order condition for this problem implies that the marginal rate of substitution between diversion and consumption is equal to their "relative price" $\alpha\left(1-\tau_{c}\right)$ :

$$
\frac{(1-q) U_{X}}{U_{C}}=\alpha\left(1-\tau_{c}\right)
$$

Using (7), we can easily derive:

Lemma 1 The utility-maximizing diversion and consumption ratio is given by

$$
\frac{X_{t}}{C_{t}}=R \equiv\left(\frac{a(1-q)^{\varphi}}{\alpha\left(1-\tau_{c}\right)}\right)^{\frac{1}{1-\varphi}}
$$

This proposition reveals that the optimal diversion rate increases with the preference for diversion $a$, and decreases with the ownership share $\alpha$ and the quality of corporate governance q. Similar results are obtained in Jensen and Meckling (1976).

Substituting (46) into (43)-(44), we can rewrite the entrepreneur's problem as

$$
V(w, y)=\max _{\left(C_{t}, \theta_{t}, T_{d}\right)} \mathbb{E}\left[\int_{0}^{T_{d}} e^{-\rho t} \frac{\left(P C_{t}\right)^{1-\gamma}}{1-\gamma} d t+e^{-\rho T_{d}} V^{d}\left(W_{T_{d}}\right)\right],
$$

subject to

$$
\mathbb{E}\left[\int_{0}^{T_{d}} \xi_{t}\left(P^{\varphi} C_{t}-\alpha\left(1-\tau_{c}\right)\left(Y_{t}-c\right)\right) d t+\xi_{T_{d}} W_{T_{d}}\right] \leq w
$$


where we define

$$
P \equiv\left[1+a^{1 /(1-\varphi)}\left(\frac{1-q}{\alpha\left(1-\tau_{c}\right)}\right)^{\varphi /(1-\varphi)}\right]^{\frac{1}{\varphi}}>1 .
$$

The parameter $P$ plays a key role in the analysis since it indicates the private benefits of control. When corporate governance is perfect $(q=1)$ or when the entrepreneur does not have preference for diversion $(a=0)$, we have $P=1$. The model then reduces to the benchmark presented in Section II.B.

As in the previous subsection, we define the shadow price process $z_{t}=z_{0} \xi_{t} e^{\rho t}$, where $z_{0}$ is the Lagrange multiplier associated with (48). We use the shadow price as the new state variable, instead of wealth. By the Lagrange multiplier method, we can easily show the following:

Proposition 3 The utility-maximizing consumption and diversion processes are respectively given by

$$
\begin{aligned}
& C_{t}=P^{(1-\varphi) / \gamma-1} z_{t}^{-1 / \gamma} \\
& X_{t}=R P^{(1-\varphi) / \gamma-1} z_{t}^{-1 / \gamma} .
\end{aligned}
$$

Note that the Lagrange multiplier $z_{0}$ is endogenous. We need to determine this value to obtain the utility-maximizing consumption and diversion processes in the preceding proposition. To this end, we apply the Saddle Point Theorem as in the previous subsection to derive

$$
V(w, y)=\min _{z_{0} \geq 0} \phi\left(z_{0}, y\right)+z_{0} w
$$

where we define the dual value function

$$
\phi(z, y)=\max _{T_{d}} \mathbb{E}\left[\int_{0}^{T_{d}} e^{-\rho t}\left(P^{-b(1-\varphi)} \tilde{u}\left(z_{t}\right)+\alpha\left(1-\tau_{c}\right)\left(Y_{t}-c\right) z_{t}\right) d t+e^{-\rho T_{d}} \phi^{d}\left(z_{T_{d}}\right)\right],
$$

where $\left(z_{0}, Y_{0}\right)=(z, y), \tilde{u}$ is given by (35), and $\phi^{d}$ is given by (39). Since $\tilde{u}$ and $\phi^{d}$ are strictly decreasing and strictly convex, so is $\phi$. Thus, there is a unique solution for $z_{0}$ in problem (52). We denote this solution as $\hat{z}_{0}=f(w, y)$.

The preceding analysis reveals that, in order to solve the default time, we only need to solve (53). Thus, the original combined stopping and control problem is simplified to a pure stopping problem (53) and a static optimization problem (52). The following lemma is useful. 
Lemma 2 Problem (53) is equivalent to the problem

$$
\begin{aligned}
\phi(z, y)= & -P^{-b(1-\varphi)} \eta \frac{z^{b}}{b}+\alpha\left(1-\tau_{c}\right)\left(\frac{y}{\delta}-\frac{c}{r}\right) z \\
& +\max _{T_{d}} \mathbb{E}\left[e^{-\rho T_{d}}\left(-\eta \frac{z_{T_{d}}^{b}}{b}\left(1-P^{-b(1-\varphi)}\right)-\alpha\left(1-\tau_{c}\right)\left(\frac{Y_{T_{d}}}{\delta}-\frac{c}{r}\right) z_{T_{d}}\right)\right] .
\end{aligned}
$$

This lemma states that the dual value function $\phi(z, y)$ is equal to the present value of the dual utility flows $-P^{-b(1-\varphi)} \eta z^{b} / b$ and equity claims $\alpha\left(1-\tau_{c}\right)(y / \delta-c / r) z$, plus an option value of exchanging these values for the dual utility after default $\phi^{d}(z)=-\eta z^{b} / b$. Thus, the exercising time of this option gives the optimal default time. Unlike the case with perfect corporate governance $(q=1)$ or the case without preference for diversion $(a=0)$, the entrepreneur derives private benefits of control in that $P>1$ by (2). It follows from (54) that the utilitymaximizing default policy depends on two state variables $z$ and $y$. Importantly, it also depends on the parameters $a, q, \alpha$ and $\gamma$, as reflected by the term $P^{-b(1-\varphi)}$.

Using the method of $\mathrm{Hu}$ and Oksendal (1998), we characterize the default policy explicitly in the following:

Proposition 4 The utility-maximizing default time is given by

$$
T_{d}^{*}=\inf \left\{t>0:\left(Y_{t}, z_{t}\right) \in \mathcal{D}\right\}
$$

where the default region is given by

$$
\mathcal{D} \equiv\left\{(y, z) \in \mathbb{R}_{+}^{2}: \chi_{1} \frac{y}{\delta}+\chi_{2} z^{-\frac{1}{\gamma}} \leq \frac{c}{r}\right\}
$$

Here, $\chi_{1}>0$ and $\chi_{2}>0$ are given by

$$
\chi_{1}=\frac{\pi_{1}-1}{\pi_{1}}, \quad \chi_{2}=\frac{\eta\left(1-P^{-b(1-\varphi)}\right)\left(\pi_{2}-b\right)}{b\left(\pi_{2}-1\right) \alpha\left(1-\tau_{c}\right)}
$$

where $\pi_{1}$ is given in (21) and

$$
\pi_{2} \equiv 0.5+\kappa^{-2}(r-\delta)+\sqrt{\kappa^{-4}\left(r-\delta+0.5 \kappa^{2}\right)^{2}+2 \delta \kappa^{-2}}>1>b .
$$

This proposition demonstrates that the entrepreneur will default if $y$ or $z^{-1 / \gamma}$ is low enough for $P>1$. The interpretation for $y$ is clear since when the cash flow $y$ is sufficiently low, the entrepreneur must inject additional cash to service debt repayment, ceteris paribus. At 
some trigger value, he prefers to default. There are two interpretations for $z^{-1 / \gamma}$. First, Proposition 3 shows that consumption and diversion are positively related to $z^{-1 / \gamma}$. Thus, when the entrepreneur's consumption rate or diversion rate from managing the firm is sufficiently low, he prefers to default, ceteris paribus. We may offer another more useful interpretation. Proposition 5 below shows that wealth is an increasing function of $z^{-1 / \gamma}$ since $\phi$ is a convex function of $z$. Eliminating $z^{-1 / \gamma}$, we can obtain the default region in terms of wealth $w$ and cash flow $y$. It is easy to show that holding $y$ fixed, the entrepreneur may default when his wealth level is sufficiently low.

We now turn to problem (52). Unfortunately, there is no explicit solution for the dual value function $\phi(z, y)$. Since it is two dimensional and involves stopping times, it is not trivial to solve $\phi(z, y)$ even numerically. ${ }^{9}$ However, since we have derived the explicit default region in Proposition 4, we can provide an explicit solution to $\phi(z, y)$ up to a numerical integration using the first passage time distribution.

To this end, we define $m\left(t ; z^{-1 / \gamma}, y\right)$ as the value of the risk neutral Brownian motion $B_{t}^{Q}$ for which the process $\left(Y_{t}, z_{t}\right)_{t \geq 0}$ hits the default boundary given in Proposition 4 for the first time starting from the initial value $(z, y)$. Then it follows from Proposition 4 that $m\left(t ; z^{-1 / \gamma}, y\right)$ solves the equation

$$
\chi_{1} \frac{y}{\delta} e^{\left(r-\delta-\frac{1}{2} \sigma_{y}^{2}\right) t+\sigma_{y} m\left(t ; z^{-1 / \gamma}, y\right)}+\chi_{2} z^{-1 / \gamma} e^{(b-1)\left(-r+\rho+\frac{1}{2} \kappa^{2}\right) t-(b-1) \kappa m\left(t ; z^{-1 / \gamma}, y\right)}=\frac{c}{r},
$$

where $b=1-1 / \gamma$. If $\sigma_{y}$ and $\kappa$ have the same sign and $c>0$, then the left hand side of equation (59) is monotonic in $m\left(t ; z^{-1 / \gamma}, y\right)$ and thus there is a unique solution for $m\left(t ; z^{-1 / \gamma}, y\right)$. If $\sigma_{y}$ and $\kappa$ have different signs, however, the entrepreneur may never default because of the negative correlation between the wealth and firm cash flow value and thus owning the firm serves as a hedge against his investment in the stock market. From now on we will focus on the case where $\sigma_{y}$ and $\kappa$ have the same sign.

Let $h\left(t ; z^{-1 / \gamma}, y\right)$ be the probability density function for the first hitting time of the risk neutral Brownian motion $B^{Q}$ to hit the moving boundary $m\left(t ; z^{-1 / \gamma}, y\right)$ (see Appendix B for the computation of $\left.h\left(t ; z^{-1 / \gamma}, y\right)\right)$. Then we have

\footnotetext{
${ }^{9}$ One may use PDE methods.
} 
Lemma 3 The dual value function is given by

$$
\begin{aligned}
& \phi(z, y)=-\eta \frac{z^{b}}{b} P^{-b(1-\varphi)}+\alpha\left(1-\tau_{c}\right)\left(\frac{y}{\delta}-\frac{c}{r}\right) z \\
& +\int_{0}^{\infty} e^{-r t}\left(-\eta \frac{z^{b}}{b}\left(1-P^{-b(1-\varphi)}\right) e^{(b-1)\left(-r+\rho+\frac{1}{2} \kappa^{2}\right) t-(b-1) \kappa m\left(t ; z^{-1 / \gamma}, y\right)}\right. \\
& \left.-\alpha\left(1-\tau_{c}\right)\left(\frac{y}{\delta} e^{\left(r-\delta-\frac{1}{2} \sigma_{y}^{2}\right) t+\sigma_{y} m\left(t ; z^{-1 / \gamma}, y\right)}-\frac{c}{r}\right) z\right) h\left(t ; z^{-1 / \gamma}, y\right) d t .
\end{aligned}
$$

This characterization provides a simple formula for $\phi(z, y)$ that is easy to compute numerically. Lemma 3 also implies that $\phi(z, y)$ is twice continuously differentiable in $z$. We can now provide the solution to the primal problem.

Proposition 5 Before default, the utility-maximizing wealth policy is given by

$$
W_{t}=-\phi_{z}\left(z_{t}, Y_{t}\right)
$$

and the utility maximizing portfolio policy is given by

$$
\theta_{t}=\sigma^{-2}(\mu-r) z_{t} \phi_{z z}\left(z_{t}, Y_{t}\right)-\phi_{z y}\left(z_{t}, Y_{t}\right) Y_{t} \sigma_{y} \sigma^{-1}
$$

Equation (62) admits the usual interpretation: The first term represents the demand for the mean-variance efficient portfolio, while the second term represents the hedging demand arising from changes in the investment opportunity set induced by changes in the cash flow process.

\section{Initial Financing and Investment Decisions}

So far, we have assumed that the entrepreneur has already made the investment and financing decisions and the firm has been set up at date zero. That is, we have fixed the ownership $\alpha$ and coupon rate $c$. We now turn to the choice of $\alpha$ and $c$. To do this, we first rewrite debt value in (13) and equity value in (14) using the explicit default region given in Proposition 4.

Lemma 4 Given state $\left(z_{0}, Y_{0}\right)=(z, y)$, coupon rate $c$ and ownership share $\alpha$, debt value is given by

$$
D(z, y)=\frac{c}{r}+\int_{0}^{\infty} e^{-r t}\left(\nu\left(1-\tau_{c}\right) \frac{y}{\delta} e^{\left(r-\delta-\frac{1}{2} \sigma_{y}^{2}\right) t+\sigma_{y} m\left(t ; z^{-1 / \gamma}, y\right)}-\frac{c}{r}\right) h\left(t ; z^{-1 / \gamma}, y\right) d t
$$


and equity value is given by

$$
\begin{aligned}
E(z, y)= & \left(1-\tau_{c}\right)\left[\frac{y}{\delta}-\eta R P^{(1-\varphi) / \gamma-1} z^{-\frac{1}{\gamma}}-\frac{c}{r}+\int_{0}^{\infty} e^{-r t}\left(-\frac{y}{\delta} e^{\left(r-\delta-\frac{1}{2} \sigma_{y}^{2}\right) t+\sigma_{y} m\left(t ; z^{-\frac{1}{\gamma}}, y\right)}\right.\right. \\
& \left.\left.+\eta R P^{(1-\varphi) / \gamma-1} z^{-\frac{1}{\gamma}} e^{(b-2)\left(-r+\rho+\frac{1}{2} \kappa^{2}\right) t-(b-2) \kappa m\left(t ; z^{-\frac{1}{\gamma}}, y\right)}+\frac{c}{r}\right) h\left(t ; z^{-\frac{1}{\gamma}}, y\right) d t\right] .
\end{aligned}
$$

Equation (63) states that debt value is equal to the present value of coupon plus the change in value upon default. Equation (64) states that equity value is equal to the present value of dividends plus the change in value upon default.

Using Proposition 5 and Lemma 4, we can rewrite the initial financing constraint as

$$
(1-\alpha) E\left(f\left(w, y_{0}\right), y_{0}\right)+D\left(f\left(w, y_{0}\right), y_{0}\right)=I-\bar{w}
$$

Given initial values of wealth $w$ and cash flow $y_{0}$, the entrepreneur chooses financing policy $(c, \alpha)$ to maximize his utility $V\left(w, y_{0}\right)$ subject to $(65)$. As in the benchmark model, we will focus on the interior solution when the net investment cost $I-\bar{w}$ lies between debt value and firm value. Denote this solution by $(\hat{c}, \hat{\alpha})$ and the corresponding value function by $\hat{V}\left(w, y_{0}\right)$.

We finally turn to the initial investment policy. The rational entrepreneur will compare the optimal utility, $V^{d}(w+\bar{w})$, obtained if he does not make the investment with the optimal

utility, $\hat{V}\left(w, y_{0}\right)$, obtained if he makes the investment. He makes the investment if $\hat{V}\left(w, y_{0}\right)>$ $V^{d}(w+\bar{w})$. Clearly, this investment rule under agency is different from the NPV rule in the benchmark model. In particular, it depends on the entrepreneur's preferences $(\gamma, a, \varphi$, and $\rho)$ and wealth $(w$ and $\bar{w})$, as well as the quality of corporate governance $q$. Thus, the agency conflict between the controlling shareholder and the outside minority shareholders creates investment distortions.

\section{Model Implications}

In order to analyze the model's quantitative implications, we first assign parameter values in a base case model. We then conduct numerical comparative static analysis based on this base case model. We choose input parameter values in all simulations below such that the entrepreneur will optimally choose to invest and set up the firm. 


\section{A A Base Case Parameterization}

We consider an entrepreneur having the following set of preference parameters. As is standard in the economics and finance literature, we set the entrepreneur's risk aversion parameter $\gamma=2$. Since there is no available information in the existing literature about the values of the other preference parameters. We simply set the subjective discount rate $\rho=0.02$, the preference for diversion $a=0.05$, and the elasticity parameter $\varphi=0.25$.

We next calibrate parameter values for investments in real terms. We consider an investment project with dividend rate $\delta=0.035$ and volatility $\sigma_{y}=0.30$. We set the initial value of cash flows $y_{0}=1$. The investment costs $I=21$. The entrepreneur has initial total wealth $w_{0}=2$. He contributes $\bar{w}=1$ and retains $w=1$. Set the expected stock return $\mu=0.06$ and the riskfree rate $r=0.01$. These values implies that the equity premium is $5 \%$, which is close to the US data. We also set the volatility of the stock return $\sigma=0.2$.

The tax advantage of debt captures both corporate and personal taxes and is set as $\tau_{c}=$ 0.15. Liquidation costs (in percentage) are defined as the firm's going concern value minus its liquidation value, divided by its going concern value, which is measured by $1-\nu$ within our model. Using this definition, Alderson and Betker (1995) and Gilson (1997) respectively report liquidation costs equal to $36.5 \%$ and $45.5 \%$ for the median firm in their samples. We simply take the average, which is about $40 \%$.

In summary, the parameter values are listed in Table I.

In Subsections B-E below, we will hold investment policy fixed and focus on the financing polices only. We relegate the analysis of investment policies to Subsection F.

\section{B Debt Value, Equity Value, Leverage and Ownership}

In our present model, debt has default risk and bankruptcy costs. As usual, debt has tax advantage. In addition, it also has two other kinds of benefits. First, increases in debt financing raise the entrepreneur's share of the equity and mitigate the agency costs from the conflict between the entrepreneur/manager and outside shareholders. This can be seen from the financing constraint (15). Holding equity value fixed, an increase in $D_{0}$ crowds out equity financing and raises ownership share $\alpha$. This increase will lower the diversion rate by Lemma 1. The second benefit of debt is related to the free cash flow argument pointed out by Jensen 
(1986). Specifically, debt commits the firm to pay out cash, and hence reduces the amount of free cash available to the entrepreneur to pursue perquisites. Thus, a utility-maximizing capital structure can be obtained by trading off the bankruptcy cost of debt against the benefit of debt discussed above.

We turn to the discussion of the determination of the ownership share. On the one hand, a higher ownership share lowers diversion and hence lowers the agency cost of equity. On the other hand, a higher ownership share exposes the entrepreneur to more equity risk. In addition, it may exposes the entrepreneur to more default risk if he takes more debt. The utility-maximizing ownership share trades off the risk diversification cost against the diversion reduction benefit.

Because the parameters $(\gamma, a, \varphi, \rho)$ describing the managerial characteristics influence managerial behavior and hence the agency costs of equity, these parameters play an important role in determining the firm's capital structure and ownership structure. We will focus on the risk aversion parameter $\gamma$ and the time horizon parameter $\rho$ since other preference parameters are hard to measure empirically. Figures 1a-f plot debt value, equity value, leverage, ownership share, perk-equity ratio, and the fraction of initial wealth invested in the stock as functions of risk aversion parameter $\gamma$. When the entrepreneur is more risk averse, he invests less in the stock market. In addition, he takes less debt in order to reduce the default risk. Thus, he must rely more on equity financing, which lowers the leverage ratio.

We next turn to the effect of changes in the impatience parameter $\rho$. A higher value of $\rho$ implies that the entrepreneur is less patient or has a shorter time horizon. Figures 2a-f plot debt value, equity value, leverage, ownership share, perk-equity ratio, and consumption-wealth ratio as functions of $\rho$. These figures reveal the following. When the entrepreneur is less patient, he consumes more and diverts more, thereby raising the agency cost of equity. Thus, he takes more debt and less equity. We also find that the ownership share has a U-shaped relationship with $\rho$. This result may reflect the following intuition. For low values of $\rho$, a less patient entrepreneur prefers more diversification and hence a smaller ownership share is desirable, while for high values of $\rho$, a less patient entrepreneur prefers more diversion and hence equity value becomes low and thus he sells less outside equity.

We finally analyze the effect of changes in the quality of corporate governance. Figures 3a-f 
plot debt value, equity value, leverage, ownership share, perk-equity ratio, and the fraction of initial wealth invested in the stock as functions of $q$. An increase in $q$ makes diversion more costly. Thus, the entrepreneur will divert less. The decreased diversion raises equity value and lowers the ownership share. Thus, the entrepreneur uses more equity financing and hence leverage ratio falls with $q$. These results are consistent with the empirical evidence documented by a number of studies. For example, La Porta et al. (2002) document that better legal protection of outside shareholders is associated with higher equity value. La Porta et al (1999) find that better legal protection of outside shareholders is associated with lower concentration of ownership and control. Zingales (1994) reports that better legal protection of outside shareholders is associated with lower private benefits of control.

\section{Credit Spread}

Credit spread $\left(c / D_{0}-r\right)$ is an important measure of the risk structure of corporate debt. Structural models of credit spread emphasize the importance of credit risk (Huang and Huang (2003)). Our model suggests that managerial characteristics such as risk aversion and impatience is also important in determining credit spread. Figure 4a plots credit spread as a function of $\gamma$. This figure reveals that credit spread has a U-shaped relationship with risk aversion. The intuition is the following. Holding coupon rate fixed, when the entrepreneur is more risk averse, he will default earlier to avoid the risk of large capital injection in the future and hence debt value will be lower. This risk premium effect will raise the credit spread, ceteris paribus. However, since the more risk averse entrepreneur perceives higher default risk, he will take less debt in the sense that the utility-maximizing coupon rate decreases with risk aversion, as illustrated in Figure 4b. This effect lowers the credit spread, ceteris paribus. The net impact of the preceding two effects depends on the magnitude of the degree of risk aversion. For low degree of risk aversion, the latter effect dominates, while for high degree of risk aversion, the former risk premium effect dominates.

We next turn to the effect of the time horizon $\rho$. As discussed in the previous section, a less patient entrepreneur takes more debt. This effect is illustrated in Figure 4c. Thus, the less patient entrepreneur faces more default risk. This result implies that the credit spread of the bond issued by his firm is higher, as illustrated in Figure 4d.

We finally analyze the effect of the quality of corporate governance $q$. Figure 4e reveals that 
credit spread decreases with $q$. As discussed in Subsection B, when corporate governance is stronger, the entrepreneur will divert less. Thus, equity value will be higher and debt value will be lower. The entrepreneur will also take less debt as illustrated in Figure 4f. Thus, default risk will be lower, implying that credit spread will be lower.

\section{Effects of Financial Markets}

In the benchmark model with perfect corporate governance analyzed in Section II.B, the stock markets do not influence the entrepreneur's financing and investment decisions. Instead, these decisions are determined by the riskfree rate and the characteristics of the project such as volatility and payout rate. In contrast, with imperfect corporate governance, the stock markets behavior influences the entrepreneur's consumption and portfolio decisions and these decisions in turn affect his investment and financing policies.

Figures 5a-f plot effects of changes in the market price of risk $\kappa$ on debt value, equity value, leverage, credit spread, the consumption-wealth ratio, and the perk-equity ratio. These changes could be due to changes in the expected stock return or in the volatility. An increase in the market price of risk raises the consumption-wealth ratio and the amount invested in the stock market. This result follows from the usual intuition in the standard Merton-style consumption/portfolio choice model. In our model, Lemma 1 implies that diversion rate is complementary to consumption. Thus, the entrepreneur will divert more if the market price of risk is higher. Higher diversion will lower equity value and raise the agency cost of equity. Thus, the entrepreneur will issue more debt to finance investment. This behavior leads to higher leverage and hence higher credit spreads.

\section{E Agency Costs and Net Worth}

In our model, the agency conflicts between the entrepreneur and the minority shareholders lower firm value relative to that in the benchmark model with perfect corporate governance. As is standard in the literature, we measure agency costs by the relative change of firm value. As analyzed in Subsection IV.B, the quality of corporate governance $q$, the stock market price of risk, and the entrepreneurial risk aversion $\gamma$ and wealth level $w$ and $\bar{w}$ affect firm value. Thus, they also determine agency costs. As illustrated in Figures 6a-c, agency costs increase with $\gamma$ and $\kappa$, and decrease with $q$. This result is consistent with the economic intuition discussed 
earlier. Specifically, when the entrepreneur is more risk averse, he takes less debt and issues more equity, thereby causing higher agency costs of equity. When the stock market price of risk is higher, the entrepreneur consumes more and diverts more, causing higher agency costs of equity. Similarly, when corporate governance is weaker, the entrepreneur diverts more and hence the agency costs of equity are higher.

Note that the entrepreneur's wealth is also important in determining agency costs. When the entrepreneur contributes more to financing the investment cost, he relies less on the costly external equity and debt financing, and thus agency costs are lower. We illustrates this result by a simple example. Suppose the entrepreneur does not make any contribution in financing the investment cost. That is, we set $w=2$, and $\bar{w}=0$. Then we find the agency costs are given by $1.76 \%$, which is higher than the the number $1.28 \%$ in the base case model. These higher agency costs also cause the entrepreneur to take more debt and less equity, thereby raising leverage from $29 \%$ to $33 \% .^{10}$

\section{F Investment Policy}

So far, we have focused on financing polices, holding investment policy fixed. We have found that the model with agency conflicts can generate cross-sectional differences of capital structure. We have also found that the model with agency conflicts may generate a leverage ratio higher than the value-maximizing ratio in the benchmark model. For example, for the base case parameters, the model with agency conflicts implies a leverage ratio of $29 \%$, which is higher than the value-maximizing ratio $23 \%$.

We now turn to the analysis of investment policy. We will show that when the entrepreneur can select investment projects, we can generate a leverage ratio lower than that in the standard Leland-style model. Suppose that the entrepreneur can choose a lower cost investment, holding everything else constant. Then the entrepreneur does not need to sell too many shares of equity in order to finance the investment. Thus, he can hold a larger fraction of ownership share, which lowers the agency cost of equity. As a result, he takes less debt. To illustrate this intuition, we set $I=11$ and hold other parameters in Table 1 fixed. We find that the leverage ratio is now given by $20 \%$.

\footnotetext{
${ }^{10}$ The role of net worth in reducing agency costs and the transmission of monetary policies have been emphasized by the macroeconomics literature since Benanke and Gertler (1989).
} 
We finally analyze the situation where the entrepreneur can choose the scale of the investment. In our model, the investment scale is represented by the initial value $y_{0}$ of the process $Y$. Suppose the investment cost is a convex function of $y_{0}$. Economic intuition suggests that the entrepreneur may overinvest in the sense that he chooses a level of investment scale less than the value-maximizing level since he prefers to invest in order to pursue private benefits of control. To illustrate this, we take a simple quadratic cost function $I=0.5 K_{v} y_{0}^{2}+K_{f}$, where $K_{v}>0$ and $K_{f}>0$ are cost parameters. We set $K_{v}=30$ and $K_{f}=5$. For the base case parameter values, we find that the utility-maximizing level of investment scale is given by 0.815 , while the value-maximizing level is given by 0.819 .

\section{Conclusion}

Conflicts of interest between insiders such as entrepreneurs/managers or controlling shareholders and outsiders such as minority shareholders are central to the analysis of modern corporation. Based on this view, we provide a dynamic contingent claims model of investment and financing policies under agency conflicts. The key insight of the model is that managerial/entrepreneurial characteristics such as risk aversion, impatience, corporate governance, and financial markets play an important role in determining equity value, credit spread, capital structure, ownership structure, and investment policy. In addition to generating results consistent with existing empirical evidence, we provide many novel predictions regarding the cross-sectional determinants of financial structure and credit spread. In particular, we show that a more risk averse or a more patient entrepreneur issues less debt and more equity. In addition, managerial risk aversion has a U-shaped relationship with credit spread. We also show that better corporate governance is associated with higher equity value, lower leverage, less concentration of ownership, and lower credit spread. Our model can also generate a low leverage ratio and high credit spread as observed in practice. 


\section{Appendices}

\section{A Proofs}

Proof of Proposition 1: The results can be easily derived as the special case of the solution in Section III with $q=1$. One can also derive the results from Leland (1994) or Goldstein et al (2001). Q.E.D.

Proof of Proposition 2: It follows from simple algebra and the solution is identical to Merton (1971). Q.E.D.

Proof of Lemma 1: It follows from (45). Q.E.D.

Proof of Proposition 3: Use the first-order condition for the problem (47) subject to (48) to derive optimal consumption. Optimal diversion then follows Lemma 1. Q.E.D.

Proof of Lemma 2: We use the strong Markov property to derive

$$
\begin{aligned}
& \mathbb{E}\left[\int_{0}^{T_{d}} e^{-\rho t}\left(P^{-b(1-\varphi)} \tilde{u}\left(z_{t}\right)+\alpha\left(1-\tau_{c}\right)\left(Y_{t}-c\right) z_{t}\right) d t+e^{-\rho T_{d}} \phi^{d}\left(z_{T_{d}}\right)\right] \\
= & \mathbb{E}\left[\int_{0}^{\infty} e^{-\rho t}\left(P^{-b(1-\varphi)} \tilde{u}\left(z_{t}\right)+\alpha\left(1-\tau_{c}\right)\left(Y_{t}-c\right) z_{t}\right) d t\right] \\
& -\mathbb{E}\left[\int_{T_{d}}^{\infty} e^{-\rho t}\left(P^{-b(1-\varphi)} \tilde{u}\left(z_{t}\right)+\alpha\left(1-\tau_{c}\right)\left(Y_{t}-c\right) z_{t}\right) d t\right]-\mathbb{E}\left[e^{-\rho T_{d}} \eta \tilde{u}\left(z_{T_{d}}\right)\right] \\
= & g(y, z)+\mathbb{E}\left[e^{-\rho T_{d}}\left(-\eta \tilde{u}\left(z_{T_{d}}\right)-g\left(Y_{T_{d}}, z_{T_{d}}\right)\right)\right],
\end{aligned}
$$

where we can show that

$$
\begin{aligned}
g(y, z) & \equiv \mathbb{E}\left[\int_{0}^{\infty} e^{-\rho t}\left(P^{-b(1-\varphi)} \tilde{u}\left(z_{t}\right)+\alpha\left(1-\tau_{c}\right)\left(Y_{t}-c\right) z_{t}\right) d t\right] \\
& =-P^{-b(1-\varphi)} \eta \frac{z^{b}}{b}+\alpha\left(1-\tau_{c}\right)\left(\frac{y}{\delta}-\frac{c}{r}\right) z
\end{aligned}
$$

for $\left(Y_{0}, z_{0}\right)=(y, z)$. Q.E.D. 
Proof of Proposition 4: Define three new processes

$$
\begin{aligned}
X_{1}(t) & =\alpha\left(1-\tau_{c}\right) \frac{c}{r} z_{t} \\
X_{2}(t) & =\alpha\left(1-\tau_{c}\right) \frac{1}{\delta} Y_{t} z_{t} \\
X_{3}(t) & =\eta \frac{z_{t}^{b}}{b}\left(1-P^{-b(1-\varphi)}\right) .
\end{aligned}
$$

They are geometric Brownian motion processes and satisfy the dynamics

$$
\begin{aligned}
& d X_{1}(t) / X_{1}(t)=-(r-\rho) d t-\kappa d B_{t}, \\
& d X_{2}(t) / X_{2}(t)=\left(\mu_{y}-(r-\rho)-\kappa \sigma_{y}\right) d t+\left(\sigma_{y}-\kappa\right) d B_{t} \\
& d X_{3}(t) / X_{3}(t)=\left(-b(r-\rho)+\frac{b(b-1)}{2} \kappa^{2}\right)-b \kappa d B_{t} .
\end{aligned}
$$

We can rewrite the stopping problem in Lemma 2 as

$$
\max _{T_{d}} E\left[e^{-\rho T_{d}}\left(X_{1}(t)-X_{2}(t)-X_{3}(t)\right)\right]
$$

This problem has been studied by Hu and Oksendal (1998). The idea is to solve two independent stopping problems separately

$$
\max _{T_{d}} E\left[e^{-\rho T_{d}}\left(X_{1}(t)-X_{2}(t)\right)\right] \text { and } \max _{T_{d}} E\left[e^{-\rho T_{d}}\left(X_{1}(t)-X_{3}(t)\right)\right] .
$$

Each problem is similar to McDonald and Siegel (1986). The two stopping regions can be easily derived as

$$
\begin{aligned}
& \left\{\left(x_{1}, x_{2}\right) \in \mathbb{R}_{+}^{2}: x_{1} \geq \mu_{12} x_{2}\right\}, \\
& \left\{\left(x_{1}, x_{3}\right) \in \mathbb{R}_{+}^{2}: x_{1} \geq \mu_{13} x_{3}\right\}
\end{aligned}
$$

where

$$
\mu_{12}=\frac{\lambda_{2}}{\lambda_{2}-1}, \mu_{13}=\frac{\lambda_{3}}{\lambda_{3}-1}
$$

and

$$
\begin{gathered}
\lambda_{2}=\frac{1}{2}-\frac{\kappa \sigma_{y}-\mu_{y}}{\sigma_{y}^{2}}+\sqrt{\left(\frac{1}{2}-\frac{\kappa \sigma_{y}-\mu_{y}}{\sigma_{y}^{2}}\right)^{2}+\frac{2\left(r-\mu_{y}+\kappa \sigma_{y}\right)}{\sigma_{y}^{2}} .} \\
\lambda_{3}=\frac{1}{2}-\frac{r-\rho-b \kappa^{2} / 2}{\kappa^{2}(b-1)}+\sqrt{\left(\frac{1}{2}-\frac{r-\rho-b \kappa^{2} / 2}{\kappa^{2}(b-1)}\right)^{2}+\frac{2\left(\rho+b(r-\rho)-b(b-1) \kappa^{2} / 2\right)}{\kappa^{2}(b-1)^{2}}} .
\end{gathered}
$$


By Theorem 4.7 of $\mathrm{Hu}$ and Oksendal (1998), we conclude that the default region is given by

$$
\left\{\left(x_{1}, x_{2}, x_{3}\right) \in \mathbb{R}_{+}^{3}: x_{1} \geq \mu_{12} x_{2}+\mu_{13} x_{3}\right\} .
$$

Using the definition of $\delta(4)$ and $b=1-1 / \gamma$, we can simplify the above expressions after some algebra to obtain the results in Proposition 4. Q.E.D.

Proof of Lemma 3: Define

$$
G(y, z)=\mathbb{E}\left[e^{-\rho T_{d}}\left(-\eta \frac{z_{T_{d}}^{b}}{b}\left(1-P^{-b(1-\varphi)}\right)-\alpha\left(1-\tau_{c}\right)\left(\frac{Y_{T_{d}}}{\delta}-\frac{c}{r}\right) z_{T_{d}}\right)\right],
$$

for $\left(Y_{0}, z_{0}\right)=(y, z)$ and the optimal stopping time $T_{d}$. Then using the risk neutral measure $Q$ and the expressions for $z_{t}$ and $Y_{t}$, we can rewrite $G$ as

$$
\begin{aligned}
G(y, z)= & \mathbb{E}^{Q}\left[e ^ { - r T _ { d } } \left(-\eta \frac{z^{b}}{b}\left(1-P^{-b(1-\varphi)}\right) e^{(b-1)\left(-r+\rho+\frac{1}{2} \kappa^{2}\right) T_{d}-(b-1) \kappa B_{T_{d}}^{Q}}\right.\right. \\
& -\alpha\left(1-\tau_{c}\right)\left(\frac{y}{\delta} e^{\left.\left.\left.\left(r-\delta-\frac{1}{2} \sigma_{y}^{2}\right) T_{d}+\sigma_{y} B_{T_{d}}^{Q}-\frac{c}{r}\right) z\right)\right] .}\right.
\end{aligned}
$$

Then the claim follows from the fact that $B_{T_{d}}^{Q}=m\left(T_{d} ; z^{-1 \gamma}, y\right)$ by equation (59) and $T_{d}$ has density function $h\left(t ; z^{-1 / \gamma}, y\right)$. Q.E.D.

Proof of Proposition 5: Use the first-order condition for (52) to derive $W_{t}=-\phi_{z}\left(z_{t}, Y_{t}\right)$. Apply Ito's Lemma to this equation and match the resulting diffusion coefficient with that in equation (9) to derive (62). Q.E.D.

Proof of Lemma 4: The proof is similar to that of Lemma 3 and hence is omitted. Q.E.D.

\section{B Derivation of Density $h\left(t ; z^{-1 / \gamma}, y\right)$}

By Durbin (1985), the first passage time density function $h(t)$ (omitting $\left(z^{-1 / \gamma}, y\right)$ ) for notational simplicity) of the Brownian motion $B_{t}^{Q}$ of the moving boundary $m(t)$ can be solved using the following integral equation

$$
h(t)=h_{1}(t)+\int_{0}^{t}\left(m^{\prime}(t)-\frac{m(t)-m(s)}{t-s}\right) f(t \mid s) h(s) d s,
$$


where

$$
f(t \mid s)=\frac{1}{\sqrt{2 \pi(t-s)}} e^{-\frac{(m(t)-m(s))^{2}}{2(t-s)}}
$$

is the conditional density function of $B_{t}^{Q}$ at $m(t)$ given that $B_{s}^{Q}=m(s)$, and

$$
h_{1}(t)=\left|\frac{m(t)}{t}-m^{\prime}(t)\right| \frac{1}{\sqrt{2 \pi t}} e^{-\frac{m(t)^{2}}{2 t}} .
$$

In the case where $m(t)$ is affine in $t$, obviously we have $h(t)=h_{1}(t)$. Therefore, $h_{1}(t)$ can be a good approximation when $m(t)$ is close to be affine. In the general case, one can perform iterative integration using equation (B.1) by first setting $h(t)=h_{1}(t)$. 


\section{References}

Alderson, M. and B. Betker, 1995, Liquidation Costs and Capital Structure, Journal of Financial Economics 39, 45-69.

Berger, Philip G., Eli Ofek, and David L. Yermack, 1997, Managerial Entrenchment and Capital Structure Decisions, Journal of Finance 52, 1411-1438.

Bernanke, B., and M. Gertler, 1989, Agency Costs, Net Worth, and Business Fluctuations, American Economic Review 79, 14-31.

Black, F. and J. M. Scholes, 1973, The pricing of options and corporate liabilities, Journal of Political Economy 81, 637-659.

Black, F. and J. Cox, 1976, Valuing Corporate Securities: Some Effects of Bond Indenture Provisions, Journal of Finance 31, 351-367.

Brennan, M., and E. Scwhartz, 1978, Corporate Income Tax, Valuation, and the Problem of Optimal Capital Structure, Journal of Business 51, 103-114.

Cadenillas, A., J. Cvitanic, and F. Zapatero, 2004, Leverage Decision and Manager Compensation with Choice of Effort and Volatility, Journal of Financial Economics 73, 71-92.

Collin-Dufresne P., and R. Goldstein, 2001, Do Credit Spreads Reflect Stationary Leverage Ratios? Journal of Finance 56, 1929-1957.

Cox, J. and C.-F. Huang, 1989, Optimal consumption and portfolio rules when asset prices follow a diffusion process, Journal of Economic Theory 49, 33-83.

Durbin, J., 1985, The First-passage density of a continuous Gaussian process to a general boundary, Journal of Applied Probability 22, 99-122.

Duffie, Darrell, and David Lando, 2001, Term structures of credit spreads with incomplete accounting information, Econometrica 69, 633-664.

Dybvig, P. and C.-F. Huang, 1988, Nonnegative Wealth, Absence of Arbitrage, and Feasible Consumption Plans, Review of Financial Studies 1, 377-401. 
Dybvig, P. and H. Liu, 2006, Lifetime Consumption and Investment: Retirement and Constrained Borrowing, working paper, Washington University in St. Louis.

Fan, H. and S. Sundaresan, 2000, Debt Valuation, Renegotiation, and Optimal Dividend Policy, Review of Financial Studies 13, 1057-1099.

Fischer, E., R. Heinkel, and J. Zechner, 1989, Dynamic Capital Structure Choice: Theory and Tests, Journal of Finance 44, 19-40.

François, P., and E. Morellec, 2004, Capital Structure and Asset Prices: Some Effects of Bankruptcy Procedures, Journal of Business 77, 387-411.

Fries, S., M. Miller and W. Perraudin, 1997, Debt in Industry Equilibrium, Review of Financial Studies 10, 39-67.

Gilson, S., 1997, Transactions Costs and Capital Structure Choice: Evidence from Financially Distressed Firms, Journal of Finance 52, 161-196.

Goldstein, Robert, Nengjiu Ju, and Hayne E. Leland, 2001, An EBIT-based model of dynamic capital structure, Journal of Business 74, 483-512.

Graham, John R., and Campbell Harvey, 2001, The Theory and Practice of Corporate Finance: Evidence from the Field, Journal of Financial Economics 60, 187-243.

Hackbarth, Dirk, Jianjun Miao, and Erwan Morellec, 2005, Capital Structure, Credit Risk and Macroeconomic Conditions, Forthcoming in Journal of Financial Economics.

Hege, U., and P. Mella-Barral, 2003, Repeated Dilution of Diffusely Held Debt, Journal of Business, forthcoming.

Henderson, V., 2005, Valuing the option to invest in an incomplete market, working paper, Princeton University.

Hu, Yaozhong and Bernt Oksendal, 1998, Optimal Time to Invest when the Price Processes are Geometric Brownians, Finance and Stochastics 2, 295-310.

Huang, J. and M. Huang, 2002, "How Much of the Corporate-Treasury Yield Spread is Due to Credit Risk? A New Calibration Approach," Working Paper, Stanford University. 
Hugonnier, J. and E. Morellec, 2005, Investment under uncertainty and incomplete markets, working paper, University of Lausanne.

Jensen, Michael C., 1986, Agency costs of free cash flow, corporate finance and takeovers, American Economic Review 76, 323-329.

Jensen, Michael C., and William H. Meckling, 1976, Theory of the firm: Managerial behavior, agency costs, and ownership structure, Journal of Financial Economics 4, 305-360.

Ju, Nengjiu, Robert Parrino, Allen M. Poteshman, and M.S. Weisbach, 2003, Horses and Rabbits? Optimal dynamic capital structure from shareholder and manager perspectives, Working paper, University of Texas at Austin.

La Porta, R., F. Lopez-de Silanes, A. Shleifer, and R. Vishny, 1998, Law and Finance, Journal of Political Economy 106, 1113-1155.

La Porta, R., F. Lopez-de Silanes, A. Shleifer, and R. Vishny, 2000, Investor protection and corporate governance, Journal of Financial Economics 58, 3-27.

La Porta, R., F. Lopez-de Silanes, A. Shleifer, and R. Vishny, 2002, Investor protection and corporate valuation, Journal of Finance 57, 1147-1170.

La Porta, R., F. Lopez-de Silanes, and A. Shleifer, 1999, Corporate ownership around the world, Journal of Finance 54, 471-517.

Lambrecht, B., 2001, The Impact of Debt Financing on Entry and Exit in a Duopoly, Review of Financial Studies 14, 765-804.

Leland, Hayne E., 1994, Corporate debt value, bond covenants and optimal capital structure, Journal of Finance 49, 1213-1252.

Leland, Hayne E., 1998, Agency costs, risk management, and capital structure, Journal of Finance 4, 1213-1243.

Leland, Hayne E. and David H. Pyle, 1977, Information Asymmetries, Financial Structure and Financial Intermediation, Journal of Finance 32, 371-387. 
Leland, Hayne E., and Klaus B. Toft, 1996, Optimal capital structure, endogenous bankruptcy, and the term structure of credit spreads, Journal of Finance 51, 987-1019.

Mcconaughy and Mishra, 1999, Founding Family Control and Capital Structure: The Risk of Loss of Control and the Aversion to Debt, Entrepreneurship: Theory and Practice 23, 53-64.

McDonald, R. and D. Siegel, 1986, The value of waiting to invest, Quarterly Journal of Economics 101, 707-728.

Mello, A. and J. Parsons, 1992, Measuring the Agency Cost of Debt, Journal of Finance 47, 1887-1904.

Merton, Robert C., 1971, Optimum Consumption and Portfolio Rules in a Continuous-Time Model, Journal of Economic Theory 3, 373-413.

Merton, R. C., 1973, Theory of rational option pricing, Bell Journal of Economics and Management Science 4, 141-183.

Merton, 1974, On the Pricing of Corporate Debt: The Risk Structure of Interest Rates, Journal of Finance 29, 449-470.

Miao, Jianjun, 2005, Optimal Capital Structure and Industry Dynamics, Journal of Finance 6, 2621-2659.

Miao, Jianjun and Neng Wang, 2005, Investment, Consumption and Hedging under Incomplete Markets, working paper, Boston University.

Modigliani, Franco, and Merton H. Miller, 1958, The cost of capital, corporation finance and the theory of investment, American Economic Review 48, 267-297.

Morellec, Erwan, 2004, Can managerial discretion explain observed leverage ratios?, Review of Financial Studies 17, 257-294.

Myers, Steward C., 1977, The determinants of corporate borrowing, Journal of Financial Economics 37, 189-238. 
Parrino, Robert, and Michael S. Weisbach, 1999, Measuring investment distortions arising from stockholder-bondholder conflicts, Journal of Financial Economics 53, 3-42.

Parrino, Robert, Allen M. Poteshman and Michael Weisbach, 2005, Measuring Investment Distortions When Risk-Averse Managers Decide Whether to Undertake Risky Projects, Financial Management 34, 21-60.

Rajan, Raghuram G., and Luigi Zingales, 1995, What do we know about capital structure? Some evidence from international data, Journal of Finance 50, 1421-1467.

Ross, Stephen A., 1977, The Determination of Financial Structure: The Incentive Signalling Approach, Bell Journal of Economics 8, 23-40.

Shleifer, Andrei, and Rober Vishny, 1997, A survey of corporate governance, Journal of Finance $52,737-783$.

Shleifer, Andrei, and Daniel Wolfenzon 2002, Investor protection and equity markets, Journal of Financial Economics 66, 3-27.

Thomsen and Pedersen, 2000, Ownership structure and economic performance in the largest European companies, Strategic Management Journal 21, 689-705.

Zingales, Luigi, 1994, The Value of the Voting Right: A Study of the Milan Stock Exchange, Review of Economic Studies 7, 125-148. 
Table I. Base case parameter values

\begin{tabular}{ll}
\hline \hline Risk aversion & $\gamma=2$ \\
Preference for diversion & $a=0.05$ \\
Elasticity & $\varphi=0.25$ \\
Discount rate & $\rho=0.02$ \\
Dividend rate & $\delta=0.035$ \\
Volatility & $\sigma_{y}=0.3$ \\
Initial value & $y_{0}=1$ \\
Investment cost & $I=21$ \\
Initial retained wealth & $w=1$ \\
Contributed wealth & $\bar{w}=1$ \\
Riskfree rate & $r=0.01$ \\
Stock volatility & $\sigma=0.2$ \\
Stock return & $\mu=0.06$ \\
Bankruptcy cost & $1-\nu=0.4$ \\
Corporate tax rate & $\tau_{c}=0.15$ \\
Quality of governance & $q=0.5$ \\
\hline \hline
\end{tabular}


Figure 1: The effects of Risk Aversion. Figures 1a-f plot debt value, equity value, leverage, ownership share, perk-equity ratio, portfolio weight as functions of risk aversion parameter $\gamma$. Input parameter values are based on Table 1 .

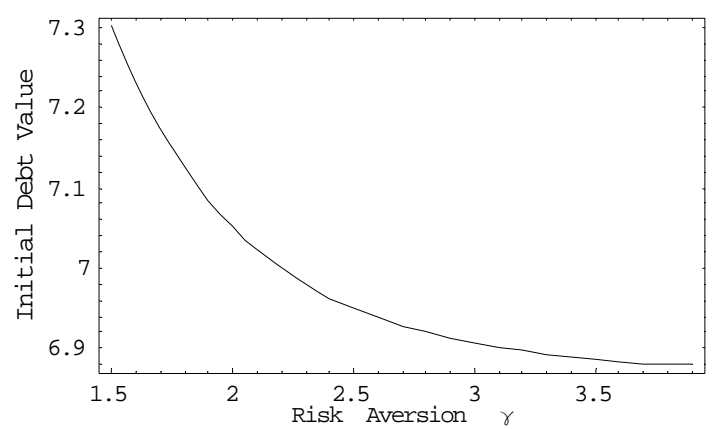

a.

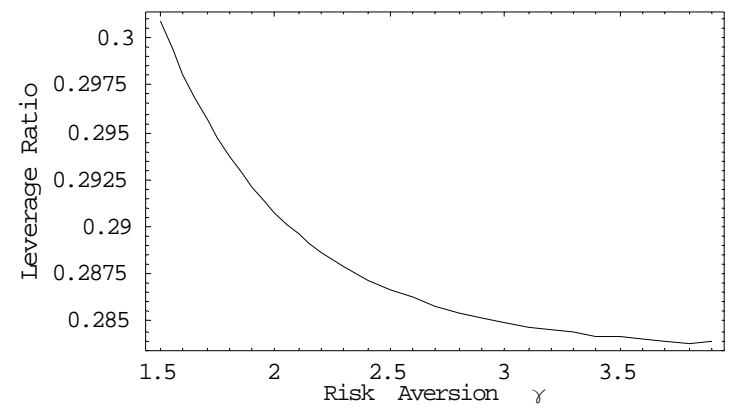

$c$.

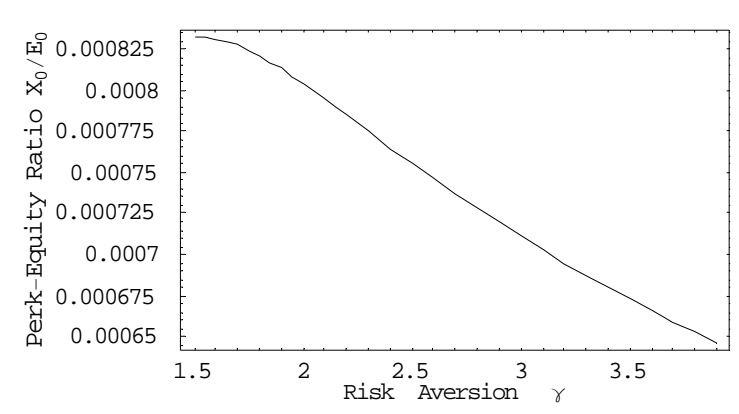

$e$.

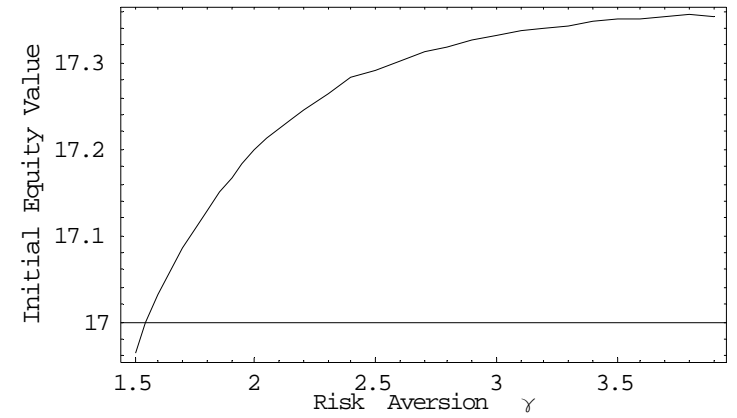

$b$.

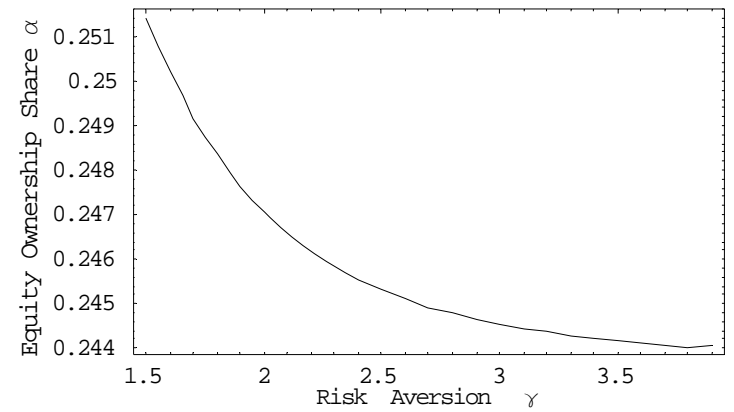

$d$.

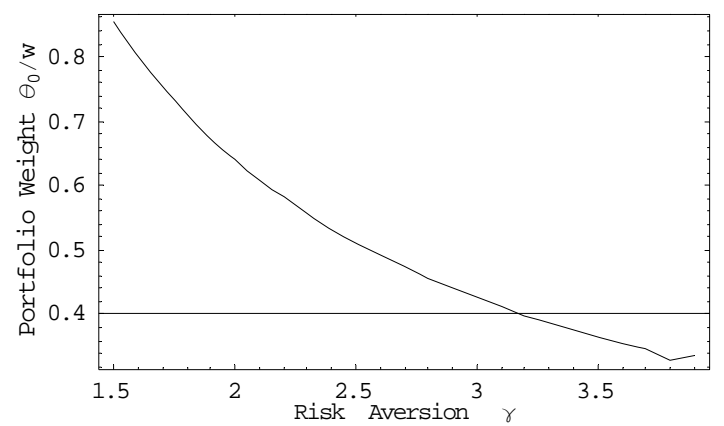

$f$. 
Figure 2: The effects of Time Discount Rate. Figures 2a-f plot debt value, equity value, leverage, ownership share, perk-equity ratio, consumption-wealth ratio as functions of the time discount rate parameter $\rho$. Input parameter values are based on Table 1.

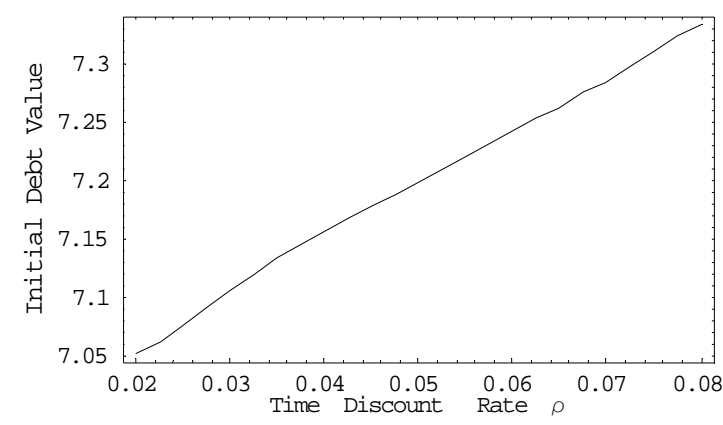

$a$.

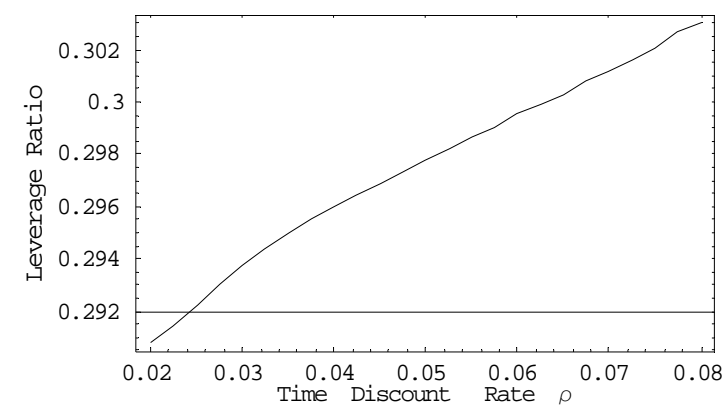

$c$.

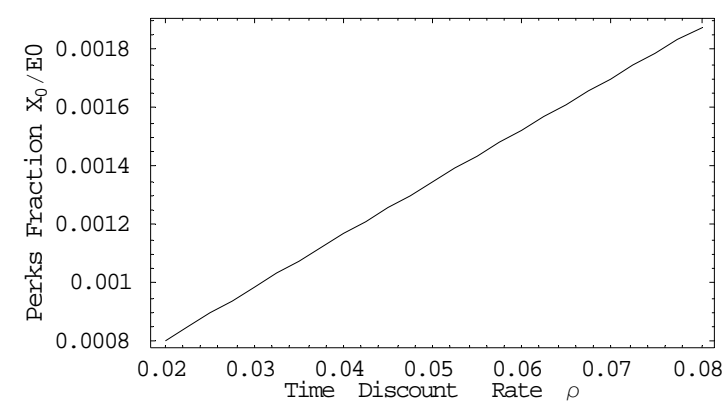

$e$.

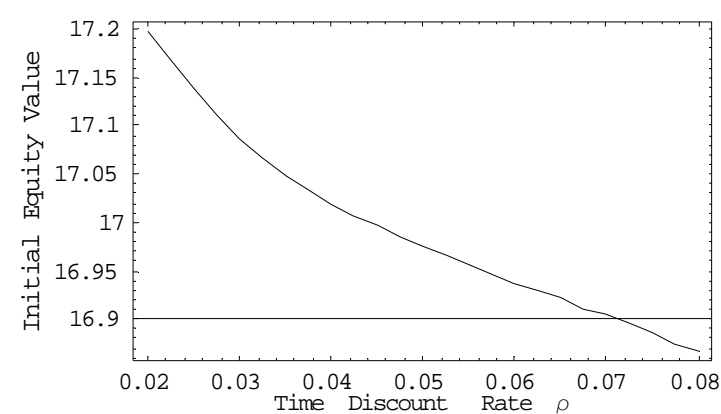

b.

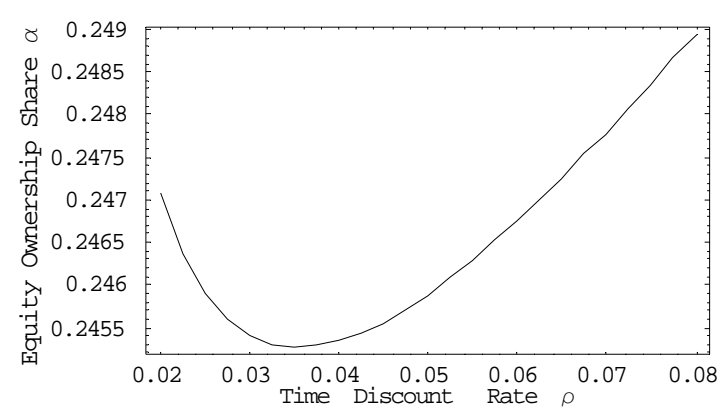

$d$.

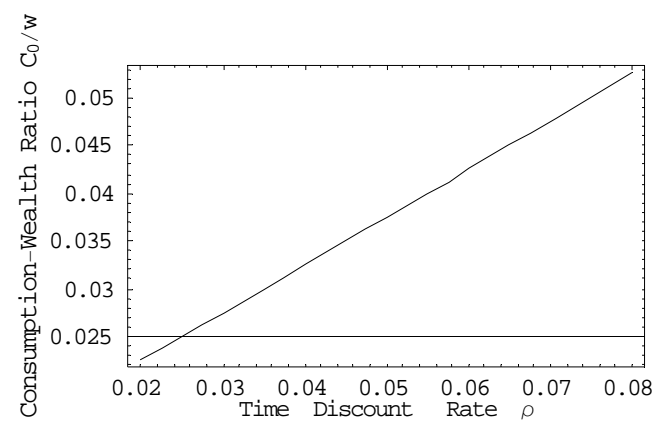

$f$. 
Figure 3: The effects of Quality of Corporate Governance. Figures 3a-f plot debt value, equity value, leverage, ownership share, perk-equity ratio, portfolio weight as functions of the quality of corporate governance $q$. Input parameter values are based on Table 1.
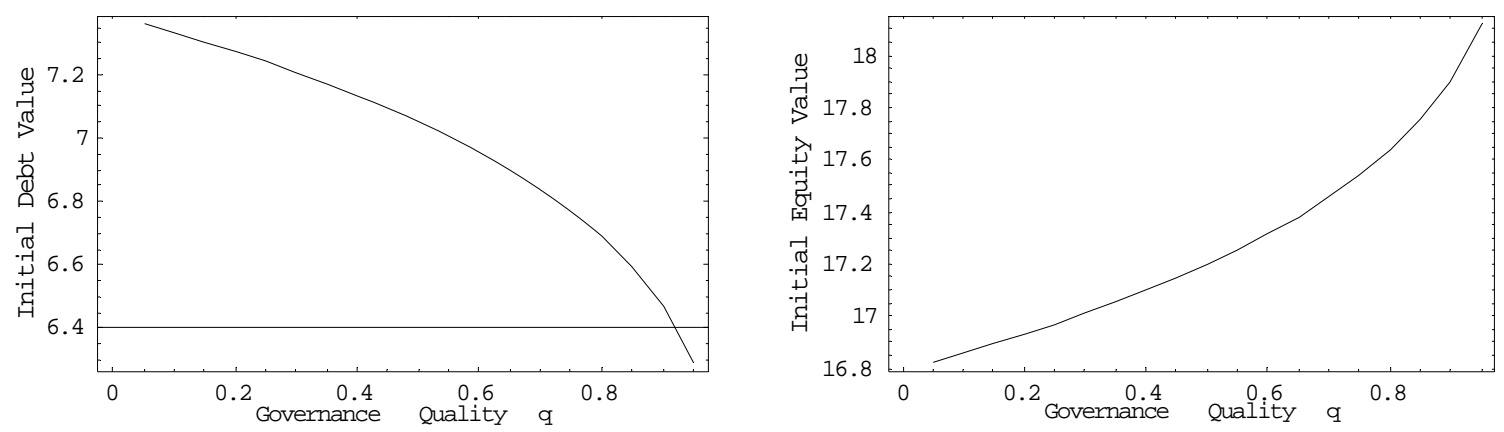

$a$.

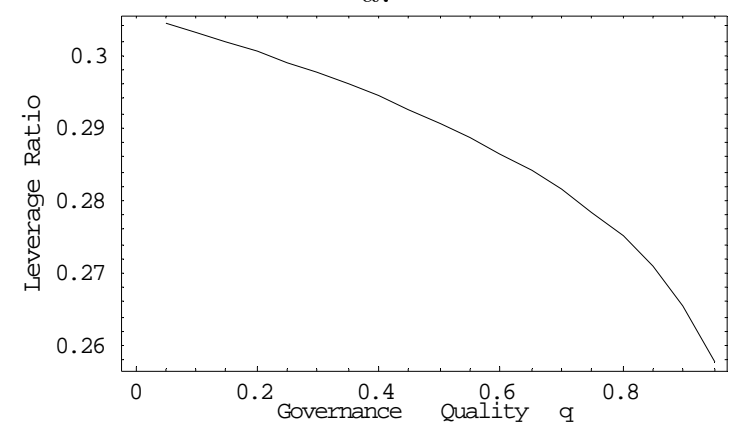

$b$.

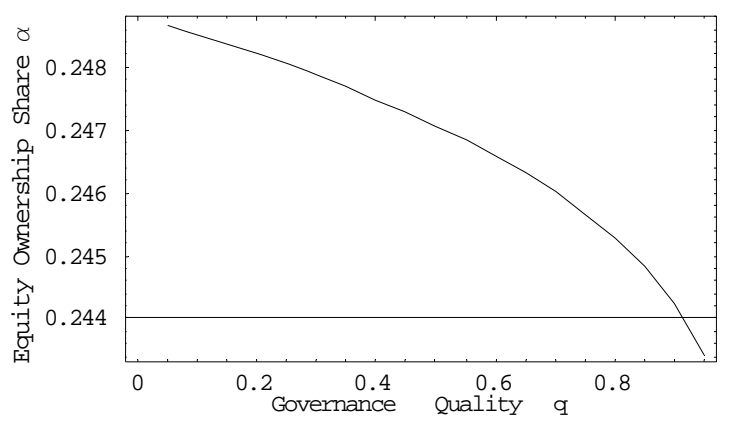

c.

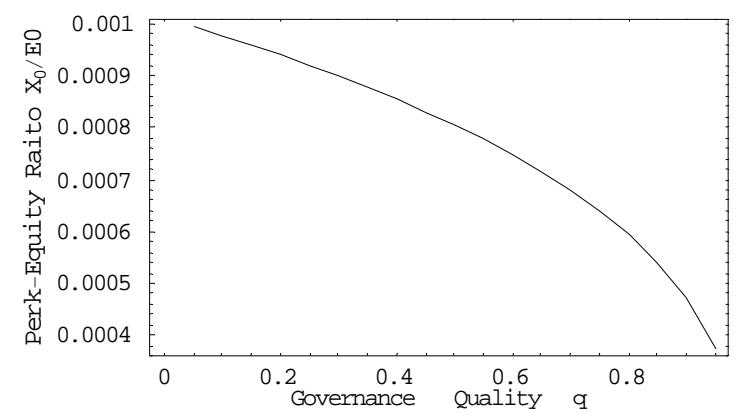

$e$.

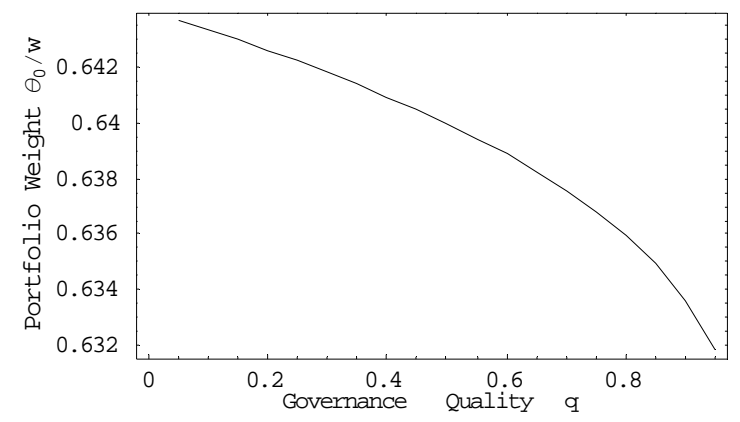

$f$. 
Figure 4: Credit Spread. Figures 4a-b plot credit spread and coupon as functions of $\gamma$. Figures 4c-d plot credit spread and coupon as functions of $\rho$. Figures 4e-f plot credit spread and coupon as functions of $q$. Input parameter values are based on Table 1.

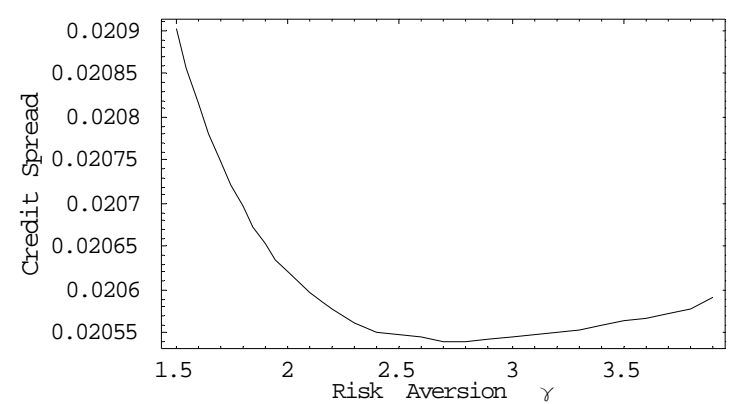

$a$.

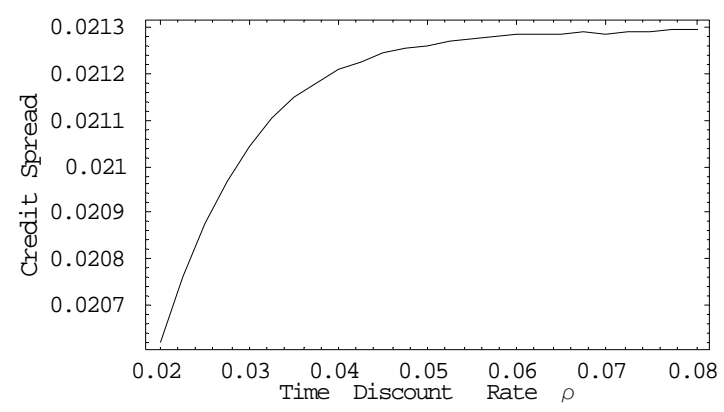

$c$.

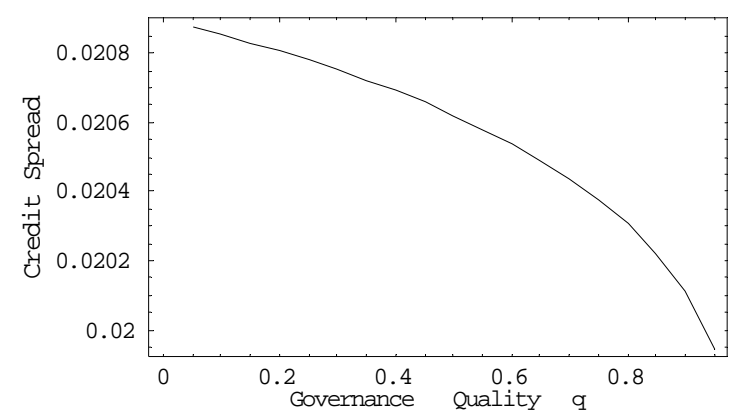

e.

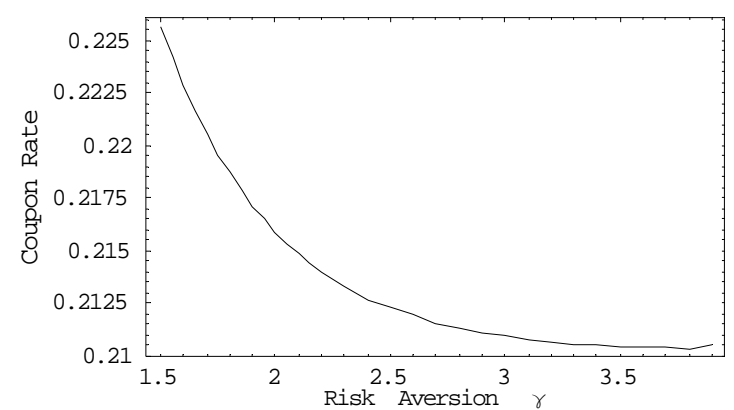

$b$.

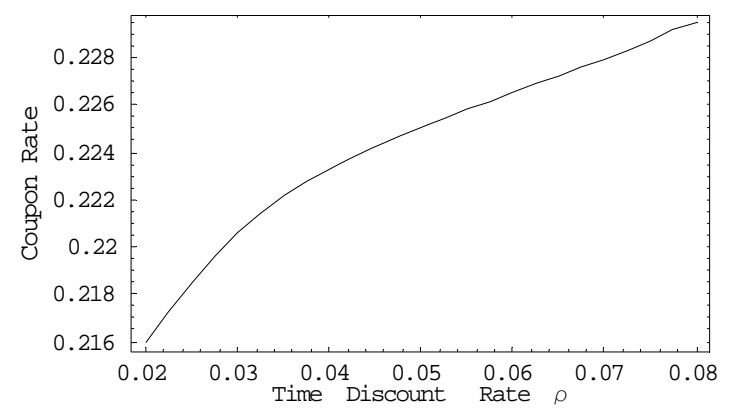

$d$.

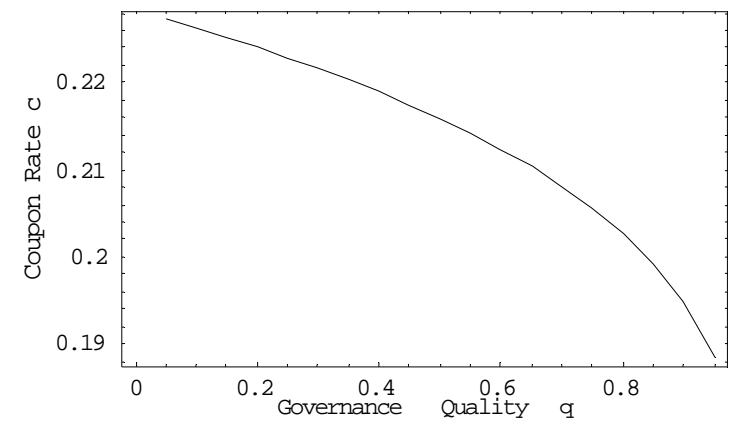

$f$. 
Figure 5: The effects of Financial Markets. Figures 5a-f plot debt value, equity value, leverage, credit spread, consumption-wealth ratio, and perk-equity ratio as functions of the Sharpe ratio $\kappa$. Input parameter values are based on Table 1.
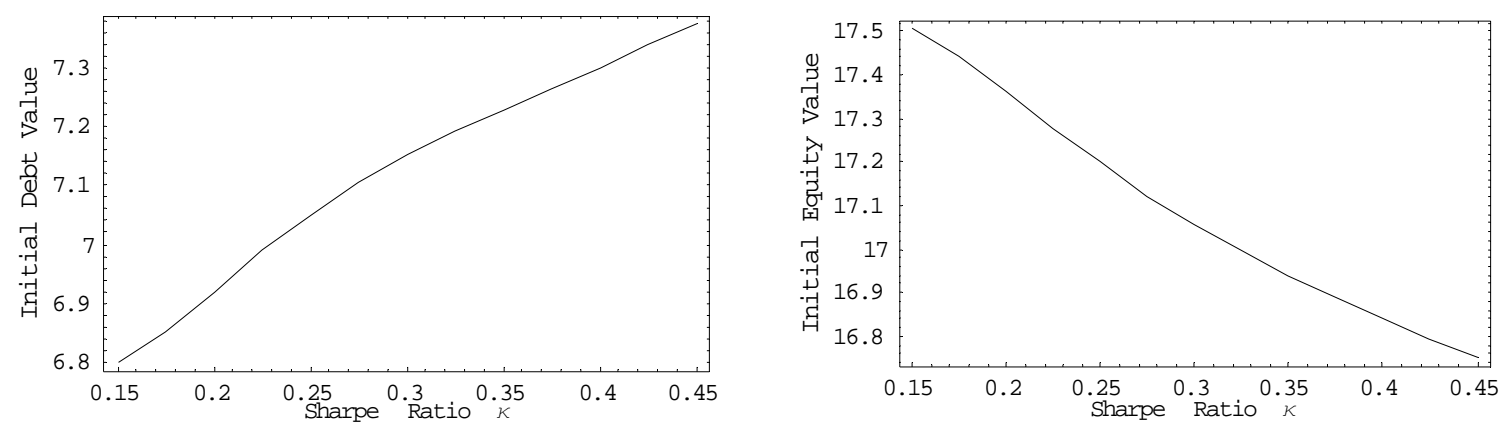

$a$.

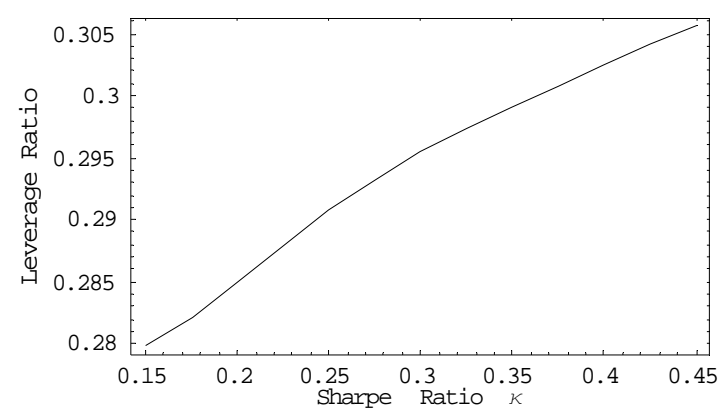

$b$.

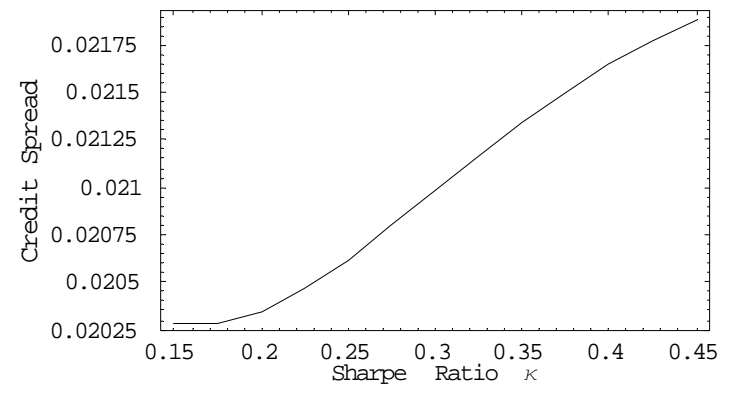

$c$.

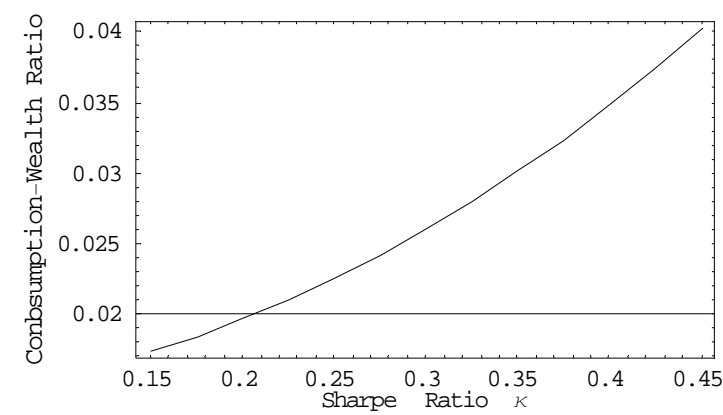

$e$.

$d$.

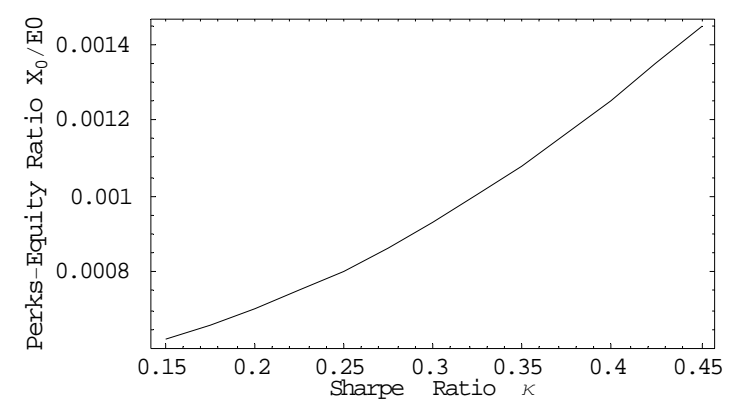

$f$. 
Figure 6: Agency Cost. Figure 6a-c plot agency costs as functions of $\gamma, q$, and $\kappa$, respectively. Input parameter values are based on Table 1.
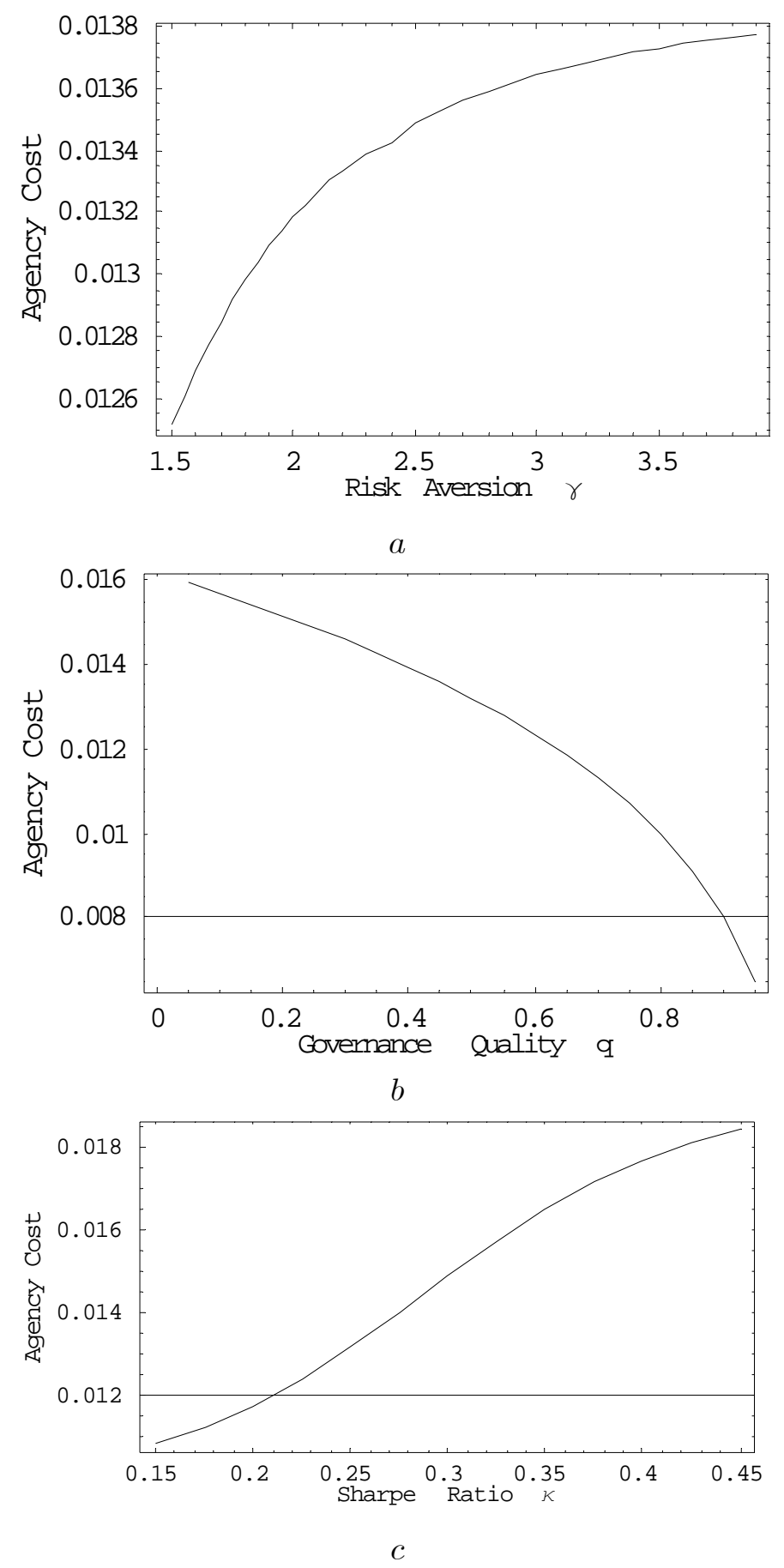